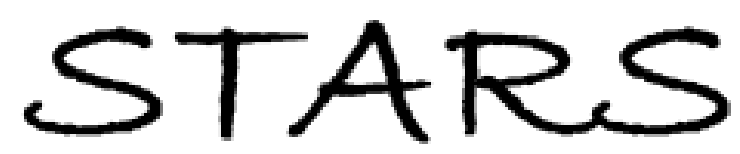

University of Central Florida

STARS

Electronic Theses and Dissertations, 2004-2019

2006

\title{
Training Wayfinding: Natural Movement In Mixed Reality
}

Ruthann Savage

University of Central Florida

Part of the Psychology Commons

Find similar works at: https://stars.library.ucf.edu/etd

University of Central Florida Libraries http://library.ucf.edu

This Doctoral Dissertation (Open Access) is brought to you for free and open access by STARS. It has been accepted for inclusion in Electronic Theses and Dissertations, 2004-2019 by an authorized administrator of STARS. For more information, please contact STARS@ucf.edu.

\section{STARS Citation}

Savage, Ruthann, "Training Wayfinding: Natural Movement In Mixed Reality" (2006). Electronic Theses and Dissertations, 2004-2019. 882.

https://stars.library.ucf.edu/etd/882

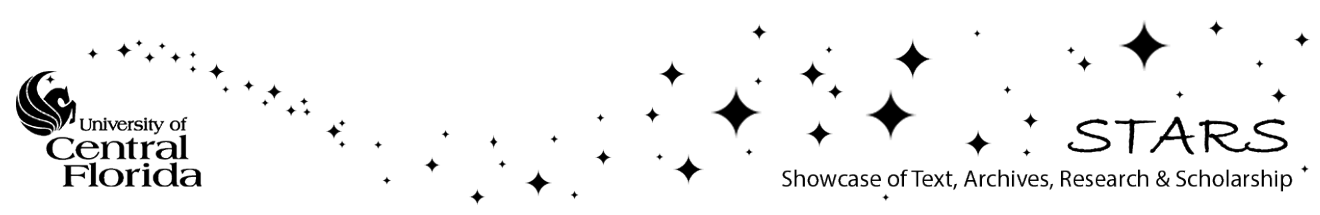




\section{RUTHANN SAVAGE}

B.A. California State University Northridge, 1987

M.A. California State University Northridge, 1994

A dissertation submitted in partial fulfillment of the requirements for the degree of Doctor of Philosophy in the Department of Psychology in the College of Sciences at the University of Central Florida Orlando, Florida

Summer Term 2006

Major Professor: Richard D. Gilson 
(C) 2006 Ruthann Savage 


\begin{abstract}
The Army needs a distributed training environment that can be accessed whenever and wherever required for training and mission rehearsal. This paper describes an exploratory experiment designed to investigate the effectiveness of a prototype of such a system in training a navigation task. A wearable computer, acoustic tracking system, and see-through head mounted display (HMD) were used to wirelessly track users' head position and orientation while presenting a graphic representation of their virtual surroundings, through which the user walked using natural movement. As previous studies have shown that virtual environments can be used to train navigation, the ability to add natural movement to a type of virtual environment may enhance that training, based on the proprioceptive feedback gained by walking through the environment.

Sixty participants were randomly assigned to one of three conditions: route drawing on printed floor plan, rehearsal in the actual facility, and rehearsal in a mixed reality (MR) environment. Participants, divided equally between male and female in each group, studied verbal directions of route, then performed three rehearsals of the route, with those in the map condition drawing it onto three separate printed floor plans, those in the practice condition walking through the actual facility, and participants in the MR condition walking through a three dimensional virtual environment, with landmarks, waypoints and virtual footprints. A scaling factor was used, with each step in the MR environment equal to three steps in the real environment, with the MR environment also broken into "tiles", like pages in an atlas, through which participant progressed, entering each tile in succession until they completed the entire route.
\end{abstract}


Transfer of training testing that consisted of a timed traversal of the route through the actual facility showed a significant difference in route knowledge based on the total time to complete the route, and the number of errors committed while doing so, with "walkers" performing better than participants in the paper map or MR condition, although the effect was weak. Survey knowledge showed little difference among the three rehearsal conditions. Three standardized tests of spatial abilities did not correlate with route traversal time, or errors, or with 3 of the 4 orientation localization tasks. Within the MR rehearsal condition there was a clear performance improvement over the three rehearsal trials as measured by the time required to complete the route in the MR environment which was accepted as an indication that learning occurred. As measured using the Simulator Sickness Questionnaire, there were no incidents of simulator sickness in the MR environment.

Rehearsal in the actual facility was the most effective training condition; however, it is often not an acceptable form of rehearsal given an inaccessible or hostile environment. Performance between participants in the other two conditions were indistinguishable, pointing toward continued experimentation that should include the combined effect of paper map rehearsal with mixed reality, especially as it is likely to be the more realistic case for mission rehearsal, since there is no indication that maps should be eliminated. To walk through the environment beforehand can enhance the Soldiers' understanding of their surroundings, as was evident through the comments from participants as they moved from MR to the actual space: "This looks like I was just here”, and "There's that pole I kept having trouble with". Such comments lead one to believe that this is a tool to continue to explore and apply. 
While additional research on the scaling and tiling factors is likely warranted, to determine if the effect can be applied to other environments or tasks, it should be pointed out that this is not a new task for most adults who have interacted with maps, where a scaling factor of 1 to 15,000 is common in orienteering maps, and 1 to 25,000 in military maps. Rehearsal time spent in the MR condition varied widely, some of which could be blamed on an issue referred to as "avatar excursions", a system anomaly that should be addressed in future research.

The proprioceptive feedback in MR was expected to positively impact performance scores. It is very likely that proprioceptive feedback is what led to the lack of simulator sickness among these participants. The design of the HMD may have aided in the minimal reported symptoms as it allowed participants some peripheral vision that provided orientation cues as to their body position and movement. Future research might include a direct comparison between this MR, and a virtual environment system through which users move by manipulating an input device such as a mouse or joystick, while physically remaining stationary.

The exploration and confirmation of the training capabilities of MR as is an important step in the development and application of the system to the U.S. Army training mission. This experiment was designed to examine one potential training area in a small controlled environment, which can be used as the foundation for experimentation with more complex tasks such as wayfinding through an urban environment, and or in direct comparison to more established virtual environments to determine strengths, as well as areas for improvement, to make MR as an effective addition to the Army training mission. 


\section{ACKNOWLEDGMENTS}

This experiment could not have been accomplished without the involvement and dedication of a number of people. Dr. Bruce Knerr and Dr. Bob Witmer, my mentors at the Army Research Institute were directly responsible for giving me this project, with the confidence that I would be able to accomplish a study that would be useful to the U.S. Army training mission. Mr. Glenn Martin and Mr. Jason Daley produced the amazingly realistic 3 dimensional computer model of the fourth floor of the Partnership II building, and were patient with my requests for tweaks, and training on the computer systems. Dr. Sherrie Jones, of USMC, PM TRASYS, made sure the secured space was accessible anytime I needed it during the week, while Colonel Robert Parrish of USMC Reserves was my escort on weekends. Mr. Kevin Oden assisted in running all 60 participants through this experiment, and I am truly grateful for his upbeat, positive attitude. Dr. Sally Stader was my sounding board; a critical listening ear that questioned and challenged, as I progressed through this dissertation process, while always being positive and supportive. I appreciate Sally more everyday.

The members of my committee deserve my special thanks for the time they spent reviewing and providing advice on my work, to be sure I was communicating as clearly as possible what I meant to communicate. Thank you, Dr. Valerie Gawron, Dr. Stephen Goldberg, Dr. Mustafa Mouloua, and Dr. Valerie Sims.

Finally, not just this dissertation, but my success in completing this degree, is the direct result of the personal and professional support of Dr. Richard Gilson. He believed in me from the beginning, even when things were at their worst. I thank him for taking a chance with me, and always believing in me, especially during those times when I didn't. 
There are people who teach without concern for students' progress. There are those who teach because it's part of having their research associated with a major university. Then there are those rare people whose entire life is an amalgam of research, invention, creativity, enthusiasm, teaching and leadership; whose mantra is “Let’s get you graduated”, and means it. I've been blessed to have "Dr. G." as my advisor and mentor, am thankful to him for all he has done, and proud to join his photo line up of graduates. 


\section{TABLE OF CONTENTS}

ABSTRACT .iii

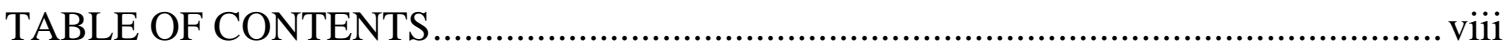

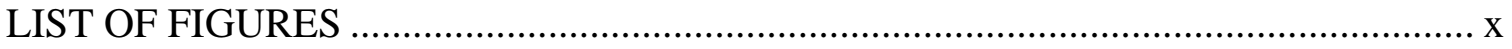

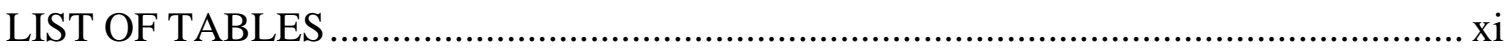

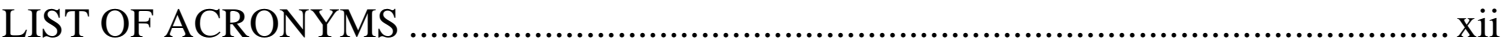

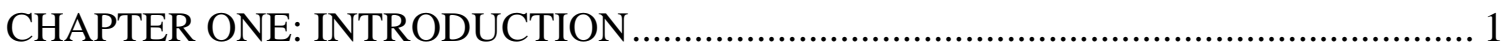

CHAPTER TWO: LITERATURE REVIEW .......................................................... 3

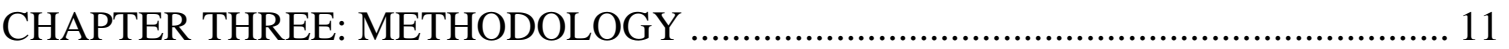

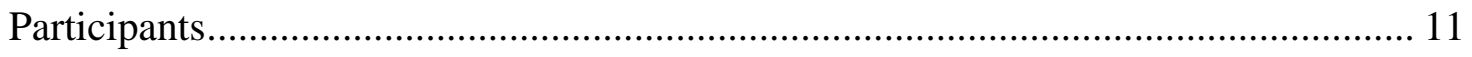

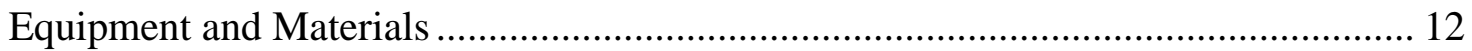

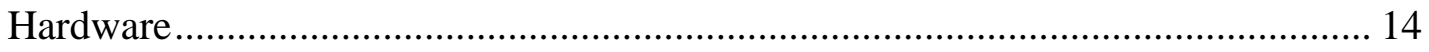

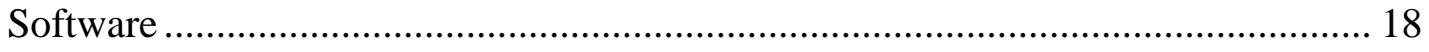

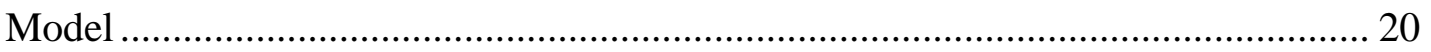

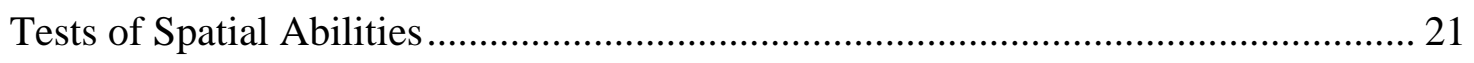

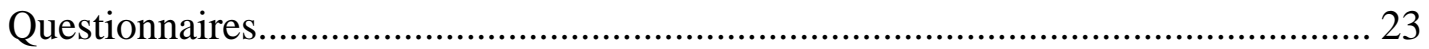

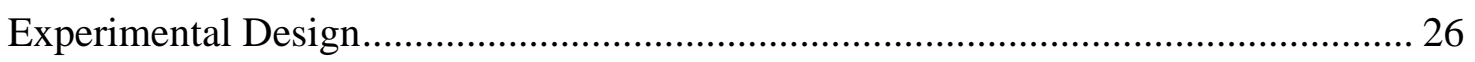

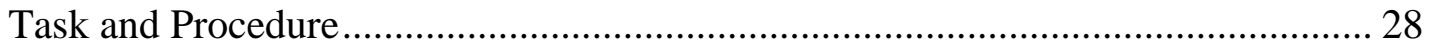

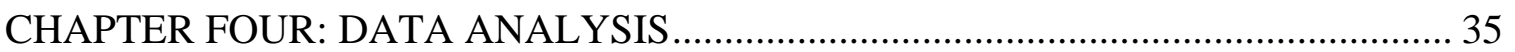

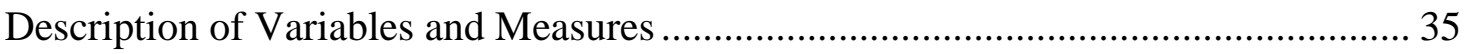

Effectiveness of MR on Performance Measures (Route and Survey Knowledge)... 39

Comparison of Spatial Abilities Tests to Performance Measures …...................... 41

Learning in Mixed Reality ............................................................................. 45 


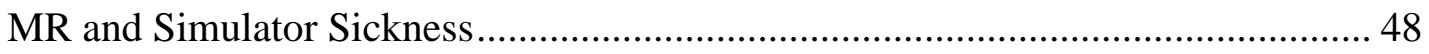

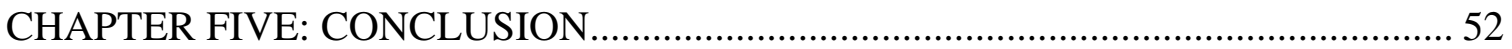

APPENDIX A: FLOOR PLAN: ROUTE, LANDMARKS AND LOCALIZATION ..... 59

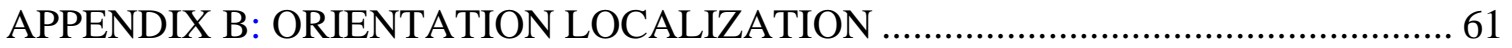

APPENDIX C: FLOOR PLAN USED FOR PAPER MAP REHEARSAL..................... 63

APPENDIX D: EXPERIMETER SCRIPTS AND PROCEDURES .............................. 65

APPENDIX E : DEMOGRAPHICS QUESTIONNAIRE …...................................... 85

APPENDIX F: ROUTE DIRECTIONS FOR MEMORIZATION .................................. 87

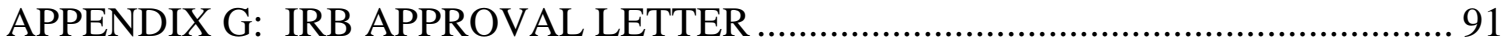

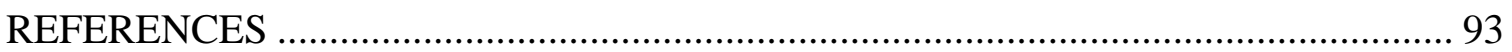




\section{LIST OF FIGURES}

Figure 1. MR Rehearsal Space and Experimenter Workstation ................................... 14

Figure 2. Quantum3D Thermite Tactical Visual Computer ....................................... 15

Figure 3. Sony Glasstron Head Mounted Display ......................................................... 16

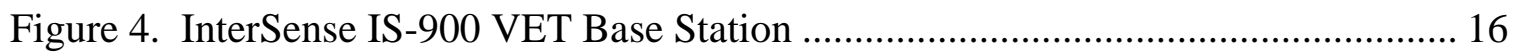

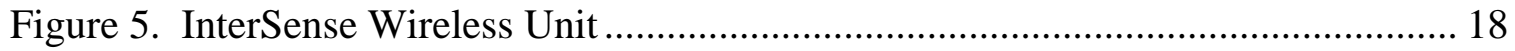

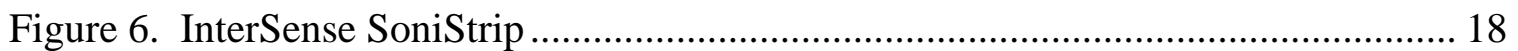

Figure 7. Moving between two sections of the route................................................. 31

Figure 8. Model Diagram Showing Tiles, Tile Coordinates and Route ........................ 46

Figure 9. Diagram of environment showing all information.................................... 60

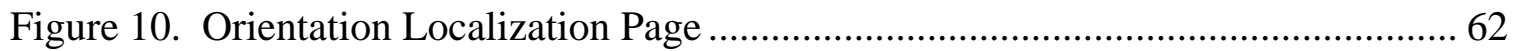

Figure 11. Floor Plan Used for Paper Map Rehearsal ............................................... 64 


\section{LIST OF TABLES}

Table 1. Situational data taken from question 15 of Motion History Questionnaire....... 24

Table 2. Simulator Sickness Questionnaire Data used in analysis of symptoms............ 26

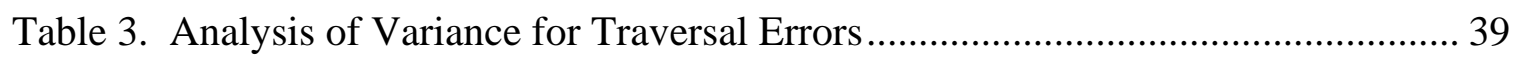

Table 4. Post Hoc with Scheffe adjustment for Traversal Errors ................................. 40

Table 5. Analysis of Variance for Time to Complete Route ........................................ 40

Table 6. Post Hoc with Scheffe adjustment for Time to Complete ............................... 40

Table 7. Analysis of Variance for Survey Knowledge .............................................. 41

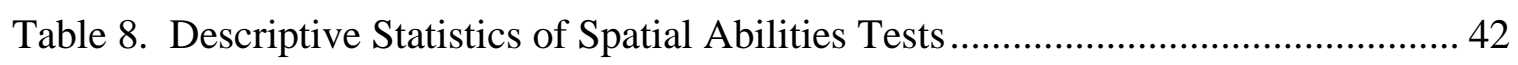

Table 9. Correlation of Spatial Abilities Tests and Route Knowledge.......................... 42

Table 10. Correlation between Spatial Abilities and Survey Knowledge Performance .. 44

Table 11. ANOVA for Time spent in each Tile over 3 Trials .................................... 47

Table 12. Means of Three Rehearsal Trial Times by Tile ......................................... 48

Table 13. ANOVA Post Test SSQ (W) Inventory .................................................... 50

Table 14. ANOVA Post Test SSQ (R) Inventory ................................................... 51 


\section{LIST OF ACRONYMS}

$\begin{array}{ll}\text { AR } & \text { Augmented Reality } \\ \text { BARS } & \text { Battlefield Augmented Reality System } \\ \text { Eds } & \text { Editors } \\ \text { EISA } & \text { Extended Industry Standard Architecture } \\ \text { GPS } & \text { Global Positioning System } \\ \text { GLONASS } & \text { Global Navigation Satellite System } \\ \text { HMD } & \text { Head Mounted Display } \\ \text { IEEE } & \text { Institute of Electrical and Electronics Engineers } \\ \text { LCD } & \text { Liquid Crystal Display } \\ \text { MR } & \text { Mixed Reality } \\ \text { MOUT } & \text { Military Operations in Urban Terrain } \\ \text { NAVAIR } & \text { Naval Air Station } \\ \text { NRL } & \text { Naval Research Laboratory } \\ \text { PCI } & \text { Peripheral Component Interconnect } \\ \text { U.S. } & \text { United States } \\ \text { UAV } & \text { Unmanned Aerial Vehicle } \\ \text { UCF } & \text { University of Central Florida } \\ \text { USMC } & \text { United States Marine Corps } \\ \text { VE } & \text { Virtual Environment }\end{array}$




\section{CHAPTER ONE: INTRODUCTION}

About thirty years ago, during training in basic map reading, a U.S. Army basic trainee listened as a drill sergeant instructed the class on map folding and layout, with the caution to keep oneself oriented by always knowing where north was in relationship to the trainee's position. If a trainees found themselves to be so misoriented that they were unable to locate any of the cardinal directions, they were told to "shake a tree, and watch it move on the map”. Since the entire class of trainees was very nervous, earnest, and intent on learning map-reading skills, this joke experienced a very flat landing. Now, however, the shake-a-tree method of orientation may have applicability while using training systems with displays of virtual environments.

The U.S. Army has a continuing need for training that ranges from basic training of new recruits through mission rehearsal, and after action reviews, that provide opportunities for immediate feedback on specific skills, tactics and strategies. The use of simulation technologies provides the opportunity to train in realistic environments without the associated expense of creating physical replications of environments of interest. Mixed reality (MR) technology, in this case providing a three dimensional virtual environment through which the user may walk as if in the actual space, has the potential to provide not only a simulated environment in which to train, but to do so while being mobile. MR has an advantage over an immersive virtual environment (VE) in that the Soldier trainee can physically move through the simulated environment using natural movements with less computer equipment than that required to generate a VE.

The system used in this experiment to present the MR was the Battlefield Augmented Reality Systems (BARS) which was developed by the Naval Research 
Laboratory, with some collaborative work with Columbia University. The intended use for BARS is to provide the wearer with information about their surroundings by presenting data from a central command center to the head mounted display, through which the wearer sees the real world with labels and or graphics. For example, a vehicle driver might have a route laid onto an austere environment where there are little or no landmarks to provide orientation or guidance. Dismounted infantry could be provided information about the location of enemy combatants that has been gathered using unoccupied aerial vehicles, and transmitted to them through a command center. BARS has been demonstrated to be compatible with both indoor tracking systems and global positioning system (GPS) technology, providing an opportunity for outdoor use.

The potential training applications of MR, as presented using BARS, or a similar system, are numerous, once the system has been demonstrated to be an effective tool in a specific training task. This experiment is an exploratory study, designed to consider the utility of using MR technology in the training of wayfinding, a basic skill required of all Soldiers, and one that has been used in previous experiments concerned with the effectiveness of training systems. 


\section{CHAPTER TWO: LITERATURE REVIEW}

The use of virtual environments (VE) in training has been explored through many efforts, each of which was a step in determining if the result of training in VE was equivalent to traditional training, while providing some additional benefit. Some of the potential benefits of training for dismounted infantry using VE identified by Nemire (1998) include the fact that regardless of whether the VE is presented using a computer workstation wherein the user navigates using a keyboard and mouse, or are fully immersive, they give the user the opportunity to interact with the environment in real time. If given the capability of interacting with the environment using manual and or speech commands the users benefit from multisensory experiences, with the potential to conduct mission planning and rehearsal on simulated battlefields, providing spatial awareness that is not available with other training media, and minimizing risk to personnel, equipment or the environment.

The use of mixed reality (MR) in training should provide the same benefits as those provided by the use of VE in training, while in addition providing the added benefit of the mobility of the technology, its smaller footprint, and reduced programming requirements. Specifically MR may be useful as a mission rehearsal tool in a theater of operations by providing the opportunity to train dismounted soldiers to navigate through a specific combat zone by providing a rehearsal space created based on information acquired through multiple sources including (unoccupied aerial vehicle) UAV reconnaissance, global positioning systems (GPS), topological maps, city plans, and building plans. 
In their discussion concerning the use of augmented reality (AR) in military operations in urban terrain (MOUT), Livingston, Brown, Gabbard, Rosenblum, Yohan, Julier, Swan and Hix (2002) saw BARS, an augmented reality system they were developing at the Naval Research Laboratory, as a possible source for embedded training for dismounted warriors. They were interested in how BARS might impact training at three levels: "as a means to blend synthetic and live forces; as a means to provide "training wheels" to show trainees critical information; and as a tool tot assist trainers in constructing and operation a training scenario” (Livingston, et al., 2002, p. 7). Given the typical size and barrenness of a current MOUT facility, BARS was suggested as a tool to add detail to the buildings, as well as to expand the size of the facility virtually, by showing the trainee additional streets and buildings through the BARS HMD. In addition to building features BARS was considered a potential source for the insertion of synthetic forces, or even live forces from a different MOUT site. The "training wheels" feature of BARS was anticipated to be helpful in identifying situations that might ultimately be fatal if a trainee did not approach the situation properly, and to provide a feedback, or re-play feature, for after action reviews and analyses of what had occurred during the training session. Finally trainers could use BARS to monitor the whereabouts of trainees that were not physically visible, or could make training scenarios more compelling and difficult.

Columbia University (2004) has performed several development demonstrations and experiments with the system they call MARS, their mobile augmented reality system, which has been in development since 1996. As technology has advanced this research group has incorporated the latest technologies. They used differential GPS until real-time 
kinematic global positioning system plus global navigation satellite system (GPS+GLONASS) became available. Their wireless network was originally built on a spread spectrum system developed internally, but now uses IEEE $802.11 \mathrm{a} / \mathrm{b}$. In a desire to use commercial off the shelf materials, this group often found themselves using items that where heavier and more bulk than they would have otherwise desired, but those were the systems that would allow the greatest amount of flexibility. They have transitioned from a FieldWorks laptop computer, with three Peripheral Component Interconnect, (PCI) and three Extended Industry Standard Architecture (EISA) expansion slots that were used to incorporate a 3D graphics adaptor and a serial port expansion card, to laptops with built in 3D graphics processors as they became common in the marketplace starting in 2001. As time has passed this program has been able to decrease the size and weight of their system while increasing the capacity and speed of the human mounted mobile computer.

BARS and MARS are closely related augmented reality systems, both of which have been demonstrated to successfully augment real world scenes, both indoors under a tracking system and outdoors using GPS systems for location data. The reduction in required computer hardware to produce an AR environment in comparison to a VE environment reduces the logistical load in shipping electronic equipment, increases flexibility in operational space requirements, and reduces demands on consumable resources such as locally generated electricity. The ability to use an AR system to create MR provides additional training and mission rehearsal opportunities by using previously developed technology in a different application, that is, providing a virtual environment through which the user can move naturally. 
If MR is as good as, or better than, traditional training, it is possible that further development efforts for MR, as a training tool would be recommended. In comparison to VE, the reduced programming requirements, the fact that the system can be human mounted and that the human moves on solid ground using natural movement, what Arthur and Hancock (2001) refer to as the added benefit of kinesthetic cues not available in maps, may make it preferable for training and mission rehearsal. One step in determining the feasibility of using MR as a mission rehearsal tool, as suggested above, is to compare its effectiveness in training navigation skills.

Exploration of VE has been shown to be at least as effective (Arthur and Hancock 2001) as spatial learning through exploration of a real world environment. While congruency between VE and the real world may be a concern given scaling issues, the relative relationships of objects, and distances between them, should accurately transfer from one environment to the other when evaluating transfer of training.

Banker (1997) in evaluating transfer of training from map study, VE combined with map study, and study in the actual environment found that the participants navigational ability had more of an effect on performance than the training condition, however, within the treatment groups those with intermediate navigational skills benefited the most from exposure to VE, while beginners appeared to be overloaded with information and experienced navigators used the VE to pinpoint specific locations or waypoints. The sample size for this study was small, but it still may point to VE as being more effective in training a navigational task than study of a paper map alone.

The complexity of the environment and path to traverse may make a difference in the effectiveness of VE as a training tool. Schlender, Peters, and Wienhofer, (2002) 
while working with a desktop VE randomly assigned participants to one of five conditions: having a map available during the entire test, only able to view the map prior to the start of the test, having textual information available throughout the test, or only prior to the start of the test and finally, no additional navigational cues. Overall, having some information available during the test was more effective than having the information available only before the start of the test.

Darken, and Sibert, (1993) used information about how both birds and humans use real world information to aid in providing cues for navigational tasks. They also considered map design, cognitive mapping principles and how cartographers and planners may use those data to select tools to be used in navigating a simple VE. They found they could make some general conclusions based on the small sample set that they studied which included that people are predictable about the way they use environmental cues. Cues are used in dividing up a space that is being searched, and to maintain directional relationships, especially for cues that are static in an environment and can be seen from anywhere within the environment. Multi-modal combinations of cues, e.g. auditory and visual, can make targets easier to find. The ability to "fly" over an environment in VE is a tool that allows the individual the opportunity to store a "bird's eye view" of the environment, which is likely to change how they explore or navigate through that environment. Thus the tool an individual uses makes a difference in their behavior and in task performance. In Darken and Sibert's (1993) work they concluded that because their navigational tasks were 2D and performed on a 2D surface, cartographers design guidelines could be used to extend characteristics of the real world 
to the virtual world. This leads them to suppose that if they had included a 3D task in their study that their 2D maps might have been less helpful.

There are generally three types of knowledge about an environment: landmark knowledge which is based on information about noticeable objects in an area, route knowledge, which is ego-referenced and acquired by personal travel through an area, and survey knowledge, which is exocentric and acquired through map memorization and or exploration of an area using different routes. Using route knowledge allows one to successfully move from one known point to another known point along a specific route, using landmarks and waypoints, but doesn't allow for deviations from the route. Route knowledge allows one to know the approximate distance between landmarks along the route they've traveled because learning is formed by sequential travel, which results in better recall when provided in the direction the route was learned, as well as the ability to give directions to guide some one else along the path (Allen and Kirasic, 1985). Route knowledge does not allow for the creation of short cuts or alternate routes through an environment.

Survey knowledge is typically acquired through multiple explorations of an environment while using different routes, through map learning, or textual information about the environment, and is characterized by the ability to take an exocentric viewpoint which is then utilized in developing a mental representation of an area as seen from a birds' eye point of view. This mental representation of a physical map is often referred to as a cognitive map (Goldin and Thorndyke, 1982). Survey knowledge built on personal experience gained through exploration of an area is a primary experience (Presson and Hazelrigg, 1984), while survey knowledge that is built through the study of maps or 
pictures is considered a secondary experience (Goldin and Thorndyke, 1982; Thorndyke and Hayes-Roth, 1982). Some studies indicate that learning survey data from paper maps is inferior to that learned through exploring the area (Presson and Hazelrigg, 1984; Scholl 1993), which is based on the orientation and location of landmarks. Having both route and survey knowledge results in complete navigational knowledge, where the distances between, and location of, landmarks are known and routes can be inferred even though they have not been traveled before.

This experiment compared the effectiveness of paper map based rehearsal, physical route rehearsal, and route rehearsal in a mixed reality environment, to achieve an acceptable level of proficiency. This was performed in a manner similar to Witmer et al (1996), in which training based on rehearsal of the actual route was compared to training based on rehearsal of the route in a virtual environment. Up to the point of this experiment there had been a small number of studies conducted that examined training accomplished in VE, with initial work investigating how performance improved with practice, but not how the training affected performance in real world settings. Resolution of detail and reduced fields of view were seen as having direct impact on the ability to use VE in training because of the resulting distance discrimination and spatial distortion issues inherent to the display devices available at that time. Locomotion was another factor that Witmer et al. considered, identifying a lack of proprioceptive feedback as a feature missing from what a user experiences when operating in the real world, a situation that could cause difficulty in estimating distance traveled, as well as lead to symptoms of simulator sickness such as nausea, dizziness or eyestrain. 
Perceived personal abilities in navigation (Cevik, 1998; Banker, 1997) and/or spatial orientation were thought to have an effect on participants' motivation and effort in learning the experimental task. Individual differences in feelings of presence or adverse reactions to computer-generated environments, such as motion sickness, were also considered as having a potential impact on participants’ acceptance of BARS as a training tool (Bernatovich, 1999; Stanney, and Salvendy, 1997). An affinity for computers and other technology used in MR systems may also be a factor if participants participate in computer-based gaming; therefore data was captured on each of these items in addition to participants’ objective performance scores. 


\section{CHAPTER THREE: METHODOLOGY}

\section{$\underline{\text { Participants }}$}

Participants for this study were 60 volunteers with 20 participants randomly assigned to each practice condition, equally divided with 10 males and 10 females in each group. The participants were recruited through various on campus communications systems, and received compensation in the form of class credit, or cash in the amount of $\$ 20.00$. Most participants were undergraduates, $47 \%$ of whom were in their first year of college, and ranged in age from 18-52. The average age was 24 , while $50 \%$ of were 18 or 19 years old. All participants reported their visual acuity as 20/20, including those using corrective lenses, and none reported visual color deficiency. Only one participant reported being ill within the past week, but felt capable of participating as the illness was a common cold that was not impairing any cognitive function.

The number of hours spent each week using a computer ranged from 2 to 60, with a mean of 25, and a standard deviation of 13.36. In addition to time spent using a computer, participants reported an average of 2.89 hours per week spent playing video games, with a range of 0 to 35 hours reported. On a scale of one to ten, 1 being never misoriented and 10 meaning they always have trouble finding their way around, participants on average rated themselves as 5 , with a range that covered the entire 10 point scale. Most participants indicated they used maps on a monthly basis (27 or 45\%), while 9 reported map usage at once a year, and 19 once a week. Five participants reported never using maps. When using a map, 55\% (33) reported orienting the map with North always “up”, or toward the top of the page. 
None of the participants were familiar with the office space used in the study as it was a secured area of the building, accessible only by personnel assigned to that space. Each participant completed three spatial abilities tests, a survey of motion sickness history, a survey of simulator sickness history, and a simulator sickness inventory prior to starting the experimental task, and additional simulator sickness inventories at critical points, including the end of their practice sessions. Participants were informed that they were permitted to decline to participate at any point in the study process without penalty.

\section{Equipment and Materials}

The route used for this experiment is in a restricted area of the fourth floor of a large office building; Partnership II, in the Central Florida Research Park, Orlando, FL. The building was five-stories, with 75,000-square-feet of space which housed the University of Central Florida (UCF) Team Performance, Cognitive Science and Simulation and Distributed Learning laboratories; the Institute for Simulation and Training offices, and offices for U.S. Navy, NAVAIR Orlando; the U.S. Army's Program Executive Office for Simulation, Training and Instrumentation; and the U.S. Marine Corps Program Manager for Training Systems. The route designed for the experiment wound through approximately 7,000 square feet of a secured area of the building made up of cubicle office spaces, to which was added 15 survey flags as landmarks, 4 each blue, white and pink, and 3 orange. The cubicle area was situated on the south side of the building, with a wall of windows on the south side of the space, and a dividing walkway on the north side that was located in the approximate center of the building. The north side of the building, opposite the cubicle area was made up of hard walled offices. The 
route was designed to be confined to the cubicle space, except for one segment of the route that entered the walkway. The route included 19 decision points: 12 turns without redundant coding, that is, only one cue given to identify the turn, and 7 intersections with no direction change.

Clipboards were hung at two specific orientation localization assessment stations along the route. Station one was located at the approximate center of the route, $145^{\circ}$ from the starting point and $209^{\circ}$ from the end.. Station two was located in the aisle furthest from the starting point, with an angle of $299^{\circ}$ from the start of the route and $329^{\circ}$ from the end of the route. Participants were instructed to stand facing the clipboard, which for station one placed them with their back to the start, while at station two they were positioned with both the start and end points in front of them. At neither position, however, were the participants able to see these points given the intervening office cubicles walls. Please see Appendix A for a diagram of the office space that shows the location of the landmarks, and the orientation localization stations. Appendix B is a copy of the diagram that was posted at each orientation localization station.

The diagram in Appendix C is a copy of the floor plan that shows the starting point and the locations of the survey flags that were used for the three practice trials by the paper map condition participants. All route direction markings, orientation localization points and accompanying directional measurement lines, the description of the environment in the lower right corner, and the end of the route have been removed from the diagram shown in Appendix A. Participants in the physical route practice condition were moved to the fourth floor USMC cubicle space, within which the 
experimenter had located the survey flag land marks. The participants were led to the starting point from which they traversed the route using the directions they had studied.

To create the interactive virtual environment used in the mixed reality condition, a unique combination of hardware, software, and virtual model was used. These components will be detailed in the following sections.

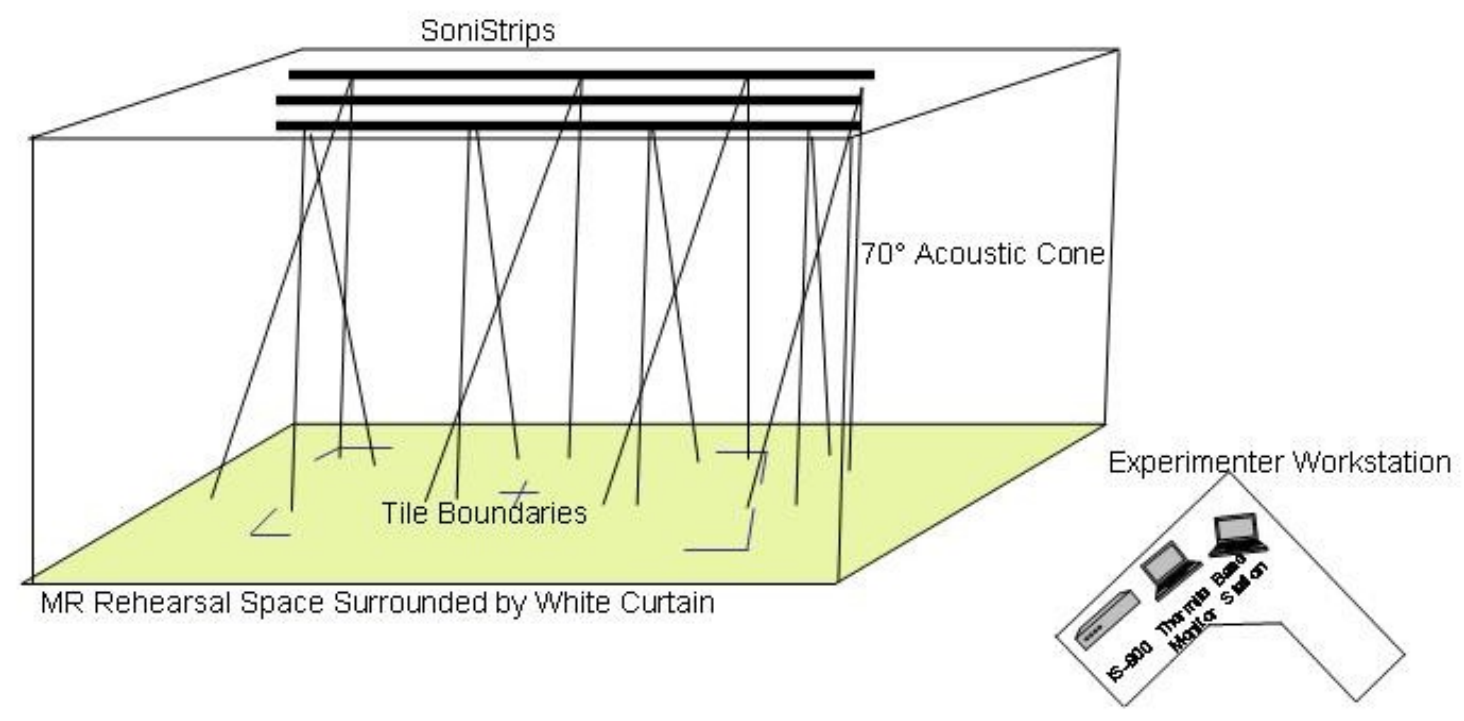

Figure 1. MR Rehearsal Space and Experimenter Workstation

\section{Hardware}

The mixed reality condition required a wearable visualization system. The system used was the hardware component of the Battlefield Augmented Reality System (BARS), created by the Naval Research Laboratory. The BARS system consists of a Quantum 3D Thermite Tactical Visual Computer (TVC) for visual simulation and rendering (Figure 1.), paired with a Sony Glasstron head-mounted display (HMD) (Figure 2.). The 
Thermite computer was equipped with a $1 \mathrm{GHz}$ Transmeta Crusoe CPU, an NVIDIA GeForce 5200 GPU, and 480 MB of RAM. While underpowered for the complexity of the environment, this configuration was sufficient to render and visualize the virtual environment at interactive frame rates of approximately 12 frames per second with latency at 0.02 seconds or less, which satisfied the requirement for a wearable visualization system. The Glasstron HMD provides a monoscopic binocular view of the environment at 800x600 pixel resolution. While the Glasstron is capable of providing an optical see-through display, this feature was not used in this work. A wireless keyboard and mouse provided input control to the Thermite.

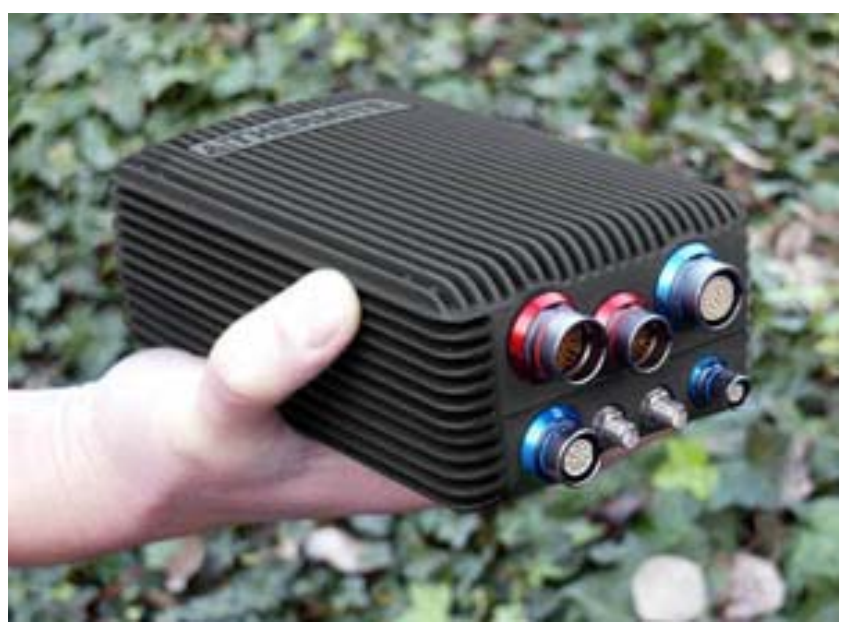

Figure 2. Quantum3D Thermite Tactical Visual Computer 


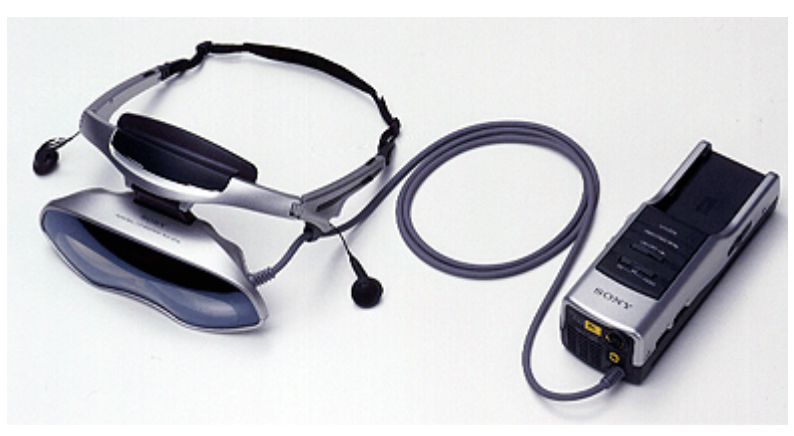

Figure 3. Sony Glasstron Head Mounted Display

A second computer was used as a base station. This was a Dell Precision 530n workstation. It was equipped with a $1.5 \mathrm{GHz}$ Pentium $4 \mathrm{CPU}$, an NVIDIA GeForce $4 \mathrm{Ti}$ 4800, and $256 \mathrm{MB}$ of RAM. This computer functioned as a host for the tracking system and provided the experimenter control, a stealth view, of the experimental environment.

For motion tracking, an InterSense IS-900VET tracking system was used (Figure 4.). This system uses a hybrid of inertial and acoustic technologies to calculate a position and orientation for each sensor worn by the user. In this work, the user wore a single wireless motion tracker (Figure 5), mounted on the display visor portion of the HMD, thus tracking the position of the user's head. The signal from the wireless sensor was transmitted to the InterSense base station, and the resulting tracking measurements were then sent back to the wearable computer via an ad-hoc $802.11 \mathrm{~b}$ connection. A $10 \times 10$ foot area was used under the IS-900 sensor strips suspended from the ceiling (Figure 6).

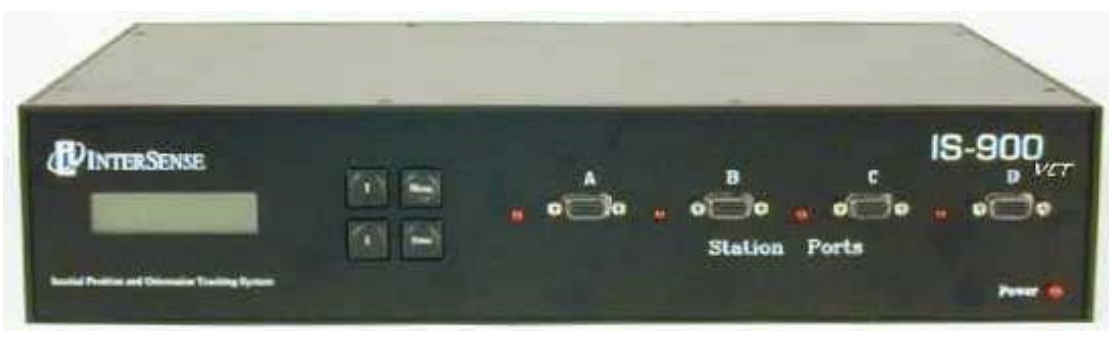

Figure 4. InterSense IS-900 VET Base Station 
The InterSense tracks the participant using six degrees of freedom which includes $\mathrm{X}, \mathrm{Y}$, and $\mathrm{Z}$ position data, along with yaw, pitch and roll orientation data. The SoniStrips have ultrasonic SoniDisc transponders that receive addressed signals from the Base Processor Unit and transmit ultrasonic pulses in response. The acoustic transmission beam width for each SoniDisc is adjusted for wide-angle coverage (approx. 70-degree cone angle) to maximize the tracking area. The IS-900 uses an acoustic time-of-flight (TOF) ranging system to prevent position and orientation drift. For maximum accuracy and resolution, acoustic range measurements are made with unidirectional measurements from the SoniStrip transmitters to the tracker.

The SoniDiscs' acoustic pulses are detected by where a command from the Processor first triggers a SoniDisc transmitter in the SoniStrips to send a $40 \mathrm{kHz}$ ultrasonic pulse, while at the same time, separate timer counters are started in the tracker and then halted by the arrival of the unique acoustic pulse signature. Using the speed of sound (which is calculated from the measured ambient temperature), range measurements are obtained and used to compute position.

The tracker is a MiniTrax tracked station operated without cabling to the IS-900 processor by using the IS-900 Wireless Module. The Wireless Module has two components: the receiver component shown below on the left, that plugs into the IS-900 Processor, and a rechargeable, battery operated transmitter that is connected to a small body worn transmitter that is attached to the HMD using hook and pile tape, and plugs directly in to the MiniTrax Station. 


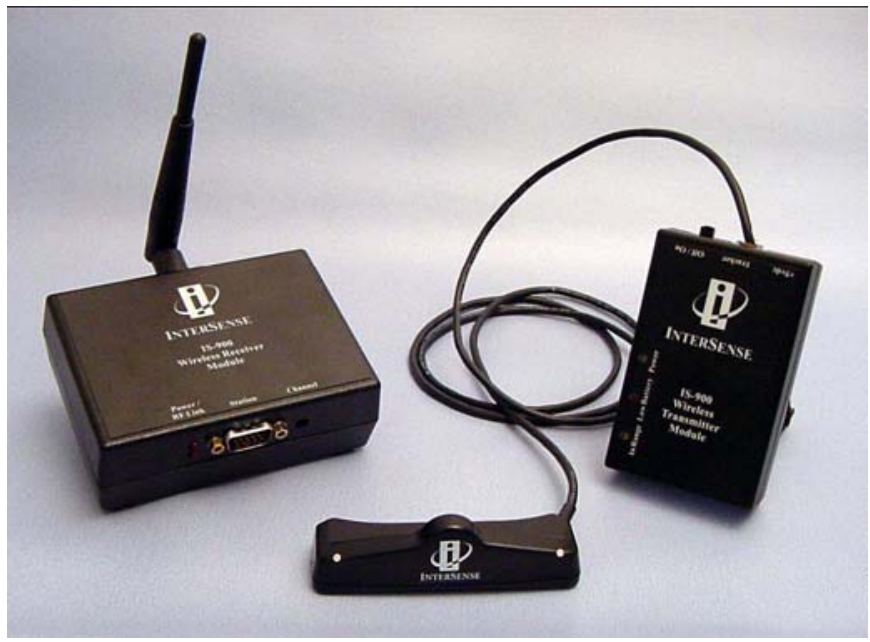

Figure 5. InterSense Wireless Unit

Figure 6. InterSense SoniStrip

\section{Software}

Although the BARS system hardware was used, the BARS software was not used in this experiment. The simulation software was based on the Virtual Environment Software Sandbox (VESS) written by the University of Central Florida Institute for Simulation and Training. This particular VESS configuration made use of the Open Scene Graph as an underlying graphics library. VESS adds the capability to drive the InterSense tracking system and convert the tracking measurements into motion in the virtual environment.

One challenge in this work was to devise a way to allow a 10x10 foot tracking area to provide a realistic walking interface for a virtual environment that was much 
larger. This challenge was addressed with two techniques. First, the user's real-world motion was scaled up by a factor of three in the virtual environment. This means that one step by the user translated into the equivalent of three steps in the virtual environment. However, the virtual environment was still larger than $30 \times 30$ feet. To address this, the software included a tiling system that allowed the user to move about in a single 30x30 foot section of the environment at a time. When the user moved outside the $10 \times 10$ foot tracking area, he or she implicitly left the current 30x30 foot tile in the virtual environment. When this happened, the user's display was blanked, and a spotter physically walked the user to the opposite edge of the tracking area. Once repositioned, the display was reactivated, and the user was free to move in the next tile of the virtual environment.

As a visual aid, the user left "footprints" in the virtual environment, showing where he or she had already walked. The footprints were shown as a texture resembling black shoe impressions drawn on the floor wherever he or she had previously been.

In addition to the virtual environment visualization capabilities, the software also included a module that collected the experimental data. The user's position and orientation were captured at 0.1 second intervals and the total route traversal time was also captured. Data was collected directly on the Thermite wearable computer.

The same software in a different configuration was used to drive the experimenter's stealth display. Instead of the first-person viewpoint the user was given, the stealth display showed the environment from above in a top-down view. An avatar was positioned on the display, showing the user's position and orientation, including the 
use of the previously described footprints. The correct route was drawn as an easy reference for the experimenter.

Due to the Thermite's limited capabilities and the complexity of the virtual environment model, the system was not capable of updating at interactive frame rates. To address this, the programmer took advantage of the nature of the virtual environment (a set of rows of cubicles), and a feature of the Open Scene Graph library, which made the environment, was amenable to a culling technique known as occlusion culling. The cubicle walls along each row as well as the walls at the ends of each row were identified as occluders in the environment. These occluders were compared with the viewpoint at each update cycle. Any geometry that was determined to be behind the occluder surfaces was not drawn. Because of the nature of the environment, occlusion culling significantly reduced the number of triangles drawn during each frame, thus helping to bring the simulation's frame rate up to interactive rates.

\section{Model}

The bulk of the virtual model was created using the original CAD designs for the building as a basis. In addition to providing floor plans for the building and showing where each row of cubicles was positioned, actual 3D cubicle furniture was provided in the CAD drawings. The AutoCAD drawings were converted into the OpenFlight format used by MultiGen Creator. After converting and assembling the various CAD models, and creating the remaining building geometry, digital photos were taken of the actual building environment and converted to texture maps. These were then applied to the models. 
Several of the CAD furniture models (those with curved surfaces) had a very high triangle count. In an effort to improve the frame rate, these heavyweight models were manually decimated (by selectively removing or combining triangles) without an appreciable loss of detail. After this was done, some of them were further decimated to create a lower level of detail that was used when the user's viewpoint was relatively far from the object.

After the basic environment was complete, it was noted that there were additional pieces of furniture and appliances, such as armchairs, copiers, laser printers, and water fountains, positioned at the ends of the cubicle rows. Since the participants could conceivably use these objects as positional cues, the most noticeable objects were modeled using measurements and digital photos as a reference. When complete, the virtual environment resembled the actual test environment with a high degree of fidelity.

\section{$\underline{\text { Tests of Spatial Abilities }}$}

Each participant completed three tests of spatial abilities. The first was the Cube Comparison test from the Manual for Kit of Factor-Referenced Cognitive Tests, (Ekstrom, et al., 1976) which is intended to measure the participants' ability to see spatial patterns or maintain their own orientation with relation to objects in space. This test, which was based on L.L. Thurstone’s work (Ekstrom, et al., 1976) on intelligence testing which used a cube comparison task, required the participant compare two cubes and determine if they were the same cube in two orientations, or two different cubes. There were two sets of 21 comparisons for which participants were allowed three minutes to 
complete. Scoring for this test consisted of the number correct answers minus the number of incorrect answers. Guessing on answers therefore was not advantageous.

The second test was also from the Manual for Kit of Factor-Referenced Cognitive Tests, (Ekstrom, et al., 1976), and was intended to measure the participants' ability to mentally manipulate or transform a diagram into another arrangement, and is known as the Surface Development Test. This test is also based on a similar test developed by L.L. Thurstone, which was also called the Surface Development test (Ekstrom, et al., 1976). For this test participants were presented with a drawing of a solid object that could be created by folding paper, while next to it was a drawing of an unfolded piece of paper, which might be folded to create the solid object. The unfolded diagram had one marking that corresponded to a mark on the solid object, and several edges of the diagram were numbered. The task was to show which of those numbered edges corresponded to the lettered edges of the solid object. There were six drawings in each of two sections with six minutes allotted for each section. The scoring method for this test stated "score on this test will be the number of correct letters minus a fraction of then number of incorrect letters” (Ekstrom, et al., 1976); however the correction factor was not identified in the manual. A search among the literature concerning tests of spatial abilities found that in their work in conducting an examination of the factor structure of the Armed Services Vocational Aptitude Battery (ASVAB), Wothke, et al. (1991) used the surface development test from the Manual by Ekstrom, et al. (1976). In a personal communication with Dr. Ruth Ekstrom, Wothke et al. (1991) were instructed to use the number of correct answers as the score for this test because the number of response alternatives varied throughout the test (Wothke et al., 1991). Based on that 
communication the surface development test for this experiment used the absolute number of correct answers as the participants' score.

The third spatial abilities test was the spatial orientation test from the GuilfordZimmerman Aptitude Survey (Guilford, 1948), which was based on work done with aircrew members during World War II. The intent of this test is to measure participants' awareness of spatial relationships, emphasizing direction of movement by using pictures of boats and relationships with the surrounding environment and the visible horizon. Two pictures are presented, the second of which shows the result of some change of position, which the participant is to describe by choosing among the five options presented. A total of 60 problems are presented for which the participant is given 10 minutes to complete as many as possible. The test score is determined by subtracting from the total number of correct answers the total number of wrong answers divided by 4 .

\section{Questionnaires}

Participants completed three questionnaires, the first of which captured demographic information. The Motion History Questionnaire was used (Kennedy, et al., 2001), RSKA Form MHQ-1, Rev. 5/01. This questionnaire captured participants’ past experience with motion sickness, asked them to compare themselves to others by estimating the likelihood of them becoming motion sick in a situation where various percentages of other people might get motion sick, and if they would volunteer for an experiment where various percentages of other people did get motion sick. On a separate page a matrix was presented that listed 14 situations in which one would experience motion, from aircraft through motorcycles, and asked the participants their preference for 
these situations (Like, Neutral or Dislike), and to mark any symptoms they had experienced in any of these situations. This questionnaire was scored as described by Kennedy, et al. (2001) with each scale that was anchored with a "never" condition scored as 0 points at the lower end and "always" or "Extremely" scored as 4 points at the higher end. Questions with "yes” or "no" answers were scored 1 or 0 respectively. The questions captured frequency of airsickness, seasickness, motion sickness under other conditions, susceptibility to motion sickness, willingness to volunteer for an experiment likely to cause motion sickness, and frequency of experiencing dizziness on an annual basis. The situations from question 15 that were used in the data analyses were scored as 1 if marked by the participants, and 0 if not marked, and limited to the following, as described by Kennedy et al. (2001):

Table 1. Situational data taken from question 15 of Motion History Questionnaire

\begin{tabular}{lrccccc}
\hline Situation & Like & Neutral & Dislike & Vomited & Nausea & No Symptoms \\
\hline Aircraft & $1 / 0$ & $1 / 0$ & $1 / 0$ & $1 / 0$ & $1 / 0$ & $1 / 0$ \\
Flight Simulator & $1 / 0$ & $1 / 0$ & $1 / 0$ & $1 / 0$ & $1 / 0$ & $1 / 0$ \\
Roller Coaster & $1 / 0$ & $1 / 0$ & $1 / 0$ & $1 / 0$ & $1 / 0$ & $1 / 0$ \\
Other Carnival Device & $1 / 0$ & $1 / 0$ & $1 / 0$ & $1 / 0$ & $1 / 0$ & $1 / 0$ \\
Long train or bus trip & N/A & N/A & N/A & N/A & N/A & $1 / 0$ \\
TOTAL & $0-4$ & $0-4$ & $0-4$ & $0-4$ & $0-4$ & $0-5$ \\
\hline
\end{tabular}

The Simulator Sickness Questionnaire (SSQ) developed by Robert S. Kennedy of RSK Assessments, Inc. was used as a screening tool to be certain that participants weren’t experiencing any symptoms of illness that might cause them to experience simulator sickness while in the MR environment, and as a monitoring tool throughout the rehearsal and transfer of training testing. The SSQ is based on a checklist of 26 symptoms, which are scored on the basis of the participants' experience of the degree of 
severity of each symptom (none, slight, moderate, severe). The highest possible score is 300, however a pre-exposure score greater than 9 is commonly used as a screening tool, at which point the participant is not exposed to a simulator or other virtual environment. The scoring procedure is used to obtain the global score intended to reflect the overall discomfort known as the Total Severity (TS) score, in addition to three subscales the provide levels of discomfort in what are intended to be diagnostic identifiers representing separable dimensions of simulator sickness (i.e., nausea, oculomotor disturbances, and disorientation) The questions from the symptom checklist that are the basis for the four measures of simulator sickness were used as discussed in Kennedy et al. (1992). The table below captures the 18 items used from the Pre and Post Exposure Symptom Checklist, with possible responses and corresponding scores for each item ranging from None $=0$, to Slight $=1$, Moderate $=2$, and Severe $=3$. These scores were then used to calculate the general simulator sickness factor of Total Severity of sickness, and the three symptom clusters of Nausea, Oculomotor and Disorientation. These values were calculated using both the original unit weighting procedure as described by Kennedy et al. (1992), and an un-weighted procedure as used by personnel at the Army Research Institute, Orlando, FL (Knerr, et al. 1998). The Post Exposure Symptom Checklist also asked participants if they had experienced a sense of motion while in the virtual environment (Yes, No, Somewhat), and to rate their own performance in the virtual environment from 1 (Poor) to 10 (Excellent). Participants were asked if they experienced any unusual events during their exposure to the virtual environment and for a description of that experience. These latter questions were evaluated separately from the symptom data. 
Table 2. Simulator Sickness Questionnaire Data used in analysis of symptoms

\begin{tabular}{|c|c|c|c|c|c|c|c|}
\hline $\begin{array}{l}\text { SSQ } \\
\#\end{array}$ & Exposure = & Baseline & Familiarization & $\begin{array}{c}\text { Rehearsal } \\
1\end{array}$ & $\begin{array}{c}\text { Rehearsal } \\
2\end{array}$ & $\begin{array}{c}\text { Rehearsal } \\
3\end{array}$ & $\begin{array}{l}\text { Post } \\
\text { Test }\end{array}$ \\
\hline 1 & G. discomfort & $\mathrm{X}$ & $\mathrm{X}$ & $\mathrm{X}$ & $\mathrm{X}$ & $\mathrm{X}$ & $\mathrm{X}$ \\
\hline 2 & Fatigue & $\mathrm{X}$ & $\mathrm{X}$ & $\mathrm{X}$ & $\mathrm{X}$ & $\mathrm{X}$ & $\mathrm{X}$ \\
\hline 5 & Headache & $\mathrm{X}$ & $X$ & $X$ & $X$ & $\mathrm{X}$ & $X$ \\
\hline 6 & Eyestrain & $X$ & $X$ & $X$ & $X$ & $\mathrm{X}$ & $X$ \\
\hline 7 & Diff. Focus & $\mathrm{X}$ & $\mathrm{X}$ & $\mathrm{X}$ & $\mathrm{X}$ & $\mathrm{X}$ & $\mathrm{X}$ \\
\hline 8 & Salivation Increase & $\mathrm{X}$ & $\mathrm{X}$ & $\mathrm{X}$ & $\mathrm{X}$ & $\mathrm{X}$ & $\mathrm{X}$ \\
\hline 9 & Cold Sweating & $\mathrm{X}$ & $\mathrm{X}$ & $\mathrm{X}$ & $\mathrm{X}$ & $\mathrm{X}$ & $\mathrm{X}$ \\
\hline 10 & Nausea & $\mathrm{X}$ & $\mathrm{X}$ & $\mathrm{X}$ & $\mathrm{X}$ & $\mathrm{X}$ & $\mathrm{X}$ \\
\hline 11 & Diff. concentrating & $\mathrm{X}$ & $X$ & $X$ & $X$ & $\mathrm{X}$ & $\mathrm{X}$ \\
\hline 13 & "Full head" & $\mathrm{X}$ & $X$ & $\mathrm{X}$ & $\mathrm{X}$ & $\mathrm{X}$ & $\mathrm{X}$ \\
\hline 14 & Blurred vision & $\mathrm{X}$ & $X$ & $X$ & $X$ & $\mathrm{X}$ & $X$ \\
\hline $15 a$ & Dizzy eyes open & $X$ & $X$ & $X$ & $X$ & $\mathrm{X}$ & $\mathrm{X}$ \\
\hline $15 b$ & Dizzy eyes closed & $\mathrm{X}$ & $\mathrm{X}$ & $\mathrm{X}$ & $\mathrm{X}$ & $\mathrm{X}$ & $\mathrm{X}$ \\
\hline 16 & Vertigo & $\mathrm{X}$ & $\mathrm{X}$ & $\mathrm{X}$ & $\mathrm{X}$ & $\mathrm{X}$ & $\mathrm{X}$ \\
\hline 20 & Stomach awareness & $\mathrm{X}$ & $\mathrm{X}$ & $\mathrm{X}$ & $\mathrm{X}$ & $\mathrm{X}$ & $X$ \\
\hline 25 & Burping & $\mathrm{X}$ & $\mathrm{X}$ & $X$ & $\mathrm{X}$ & $\mathrm{X}$ & $\mathrm{X}$ \\
\hline 27 & Other & $\mathrm{X}$ & $\mathrm{X}$ & $\mathrm{X}$ & $\mathrm{X}$ & $\mathrm{X}$ & $\mathrm{X}$ \\
\hline \multicolumn{8}{|c|}{ SSQ Scoring } \\
\hline TS & & 0 & 0 & 0 & 0 & 0 & 0 \\
\hline $\mathrm{N}$ & & 0 & 0 & 0 & 0 & 0 & 0 \\
\hline $\mathrm{O}$ & & 0 & 0 & 0 & 0 & 0 & 0 \\
\hline $\mathrm{D}$ & & 0 & 0 & 0 & 0 & 0 & 0 \\
\hline \multicolumn{8}{|c|}{ ARI Symptom Scoring } \\
\hline TS & & 0 & 0 & 0 & 0 & 0 & 0 \\
\hline $\mathrm{N}$ & & 0 & 0 & 0 & 0 & 0 & 0 \\
\hline $\mathrm{O}$ & & 0 & 0 & 0 & 0 & 0 & 0 \\
\hline $\mathrm{D}$ & & 0 & 0 & 0 & 0 & 0 & 0 \\
\hline
\end{tabular}

\section{Experimental Design}

\section{Research Questions}

The consideration of a MR environment as a training system generated a series of research questions, some of which have to do with the effectiveness of such a training tool, as measured through transfer of training testing, while others are concerned with the 
experience of the individuals interacting with the MR, including the possible occurrence of simulator sickness. These questions led to the formation of the following hypotheses:

1. Rehearsing a wayfinding task using MR will result in effective route and or survey knowledge, based on performance scores that are comparable to those achieved through rehearsal that is based on drawing a route on a floor plan (a paper map), or rehearsal in the actual test environment.

2. The spatial abilities tests Cube Comparison, and Surface Development from the Manual for Kit of Factor-Referenced Cognitive Tests, (Ekstrom, et al., 1976), and the Guilford-Zimmerman Aptitude Survey test of spatial orientation (Guilford, 1948) will correlate with participants' performance on the three performance measurement tasks of time to traverse the learned route, number of errors committed in the timed trial of route traversal, and the ability be oriented enough to locate the position of the beginning and ending of the route from two separate locations along the route.

3. Rehearsal of route traversal in the mixed reality environment will be successful as a training tool as evidenced by the improved performance, measured by decreased total time for each successive trial in the mixed reality environment.

4. Participation in route rehearsal in the MR environment will not cause greater symptomology of simulator sickness than in the non-MR environments, based on the proprioceptive feedback provided by physically walking through the virtual environment, reducing the vestibular conflict brought on by sensing motion visually, while remaining physically stationary. 


\section{Task and Procedure}

The experimental task was to train participants through the use of three different rehearsal conditions to traverse a specific path through a complex area as quickly and accurately as possible, while also demonstrating an exocentric, or survey knowledge of the surrounding environment. A direct comparison between the three rehearsal conditions (drawing the studied route on a floor plan, walking through the physical route as rehearsal and MR rehearsal) was undertaken by capturing participants' route traversal time, and by counting errors in route traversal, (i.e. wrong turns). In addition, error data was collected concerning participants' localization orientation; that is their ability to identify the location of the start and end of the route in reference to their current position.

Participants in each condition were greeted and randomly assigned to one of the three rehearsal conditions. After reading and completing an informed consent form, each participant was asked to complete each of the following items in turn: Demographics Questionnaire, Motion History Questionnaire, and Simulator Sickness Questionnaire with Baseline Exposure Symptom Checklist. Each participant then completed three tests of spatial abilities, as follows: Cube Comparison, Surface Development, and the GuilfordZimmerman Spatial Orientation subtest. Upon completion of all of the above each participant was presented with a short description of the experiment that varied according to which of the three rehearsal conditions they had been assigned. Once the participant indicated that they understood the rest of the experiment and that they were willing to proceed, they were presented with written directions that described the route they were to learn. Each participant was allotted 15 minutes to study these directions, after which the directions were removed. Participants were not permitted any aids for memorization and 
were not to write out the directions or draw what they believed the route to be based on their reading the directions.

Paper Map Condition: Participants in the paper map practice condition rehearsed the route by drawing the route they had learned through memorizing the directions, on a printed floor plan of the office space environment that showed walkways, landmarks and waypoints. The participants were allotted three practice trails under the supervision of the experimenter who identified errors as they were committed by saying, "Stop". Errors were identified as soon as it was clear that the participant was committed to a particular movement. For example if the participant were to turn right at an intersection instead of left, the experimenter would wait until the participant had started to draw the line that would connect them to what they thought the next landmark was before stopping the participant. The participant would return their pencil to the last known correct point and attempt a different strategy, without being told what the next move should be by the experimenter. This procedure was repeated as necessary to move the participant through the rehearsal phase, after which, the participant was moved to the actual office space on the fourth floor of the Partnership II building, from the laboratory space on the third floor of the same building, to perform a single timed and scored traversal of the actual physical route.

Walking condition: Participants in the rehearsal condition known as "walkers," would execute three practice traversals of the route in the actual facility. During this rehearsal phase any errors committed by the participant were identified to the participant by the experimenter saying, "Stop,” after it was clear that the participant was committed to a particular erroneous movement. For example if the participant were to turn right at 
an intersection instead of left, the experimenter would wait until the participant had taken two steps in the wrong direction before stopping them. At that point the participant was moved back to their last correct position and instructed to proceed from there, repeating this procedure as necessary to move the participant through the three practice traversals of the route. After the third rehearsal of the route with corrections, the participant would perform a single timed and scored traversal of the route.

MR condition: Participants in the MR condition also executed three practice traversals of the identified route as it was presented in the third floor laboratory space. The training area was an empty indoor space, approximately 15 feet by 15 feet, with beige carpet, and surrounded by a white curtain, with InterSense IS-900 SoniStrips installed overhead. Because the MR space was approximately 10 feet by 10 feet, it was much smaller than what would have been required to encompass the entire route used in this experiment. Two techniques were used to present the virtual version of the actual environment in the smaller space. A scaling factor was introduced, such that each step in the MR environment was equal to three steps in the actual environment. After the application of the scaling factor, the actual space was divided into six chunks, or tiles, that resembled the pages of an atlas. For example, as shown in Figure 6, the route through the first tile might start at the top of the right quadrant and end in the bottom left quadrant. 


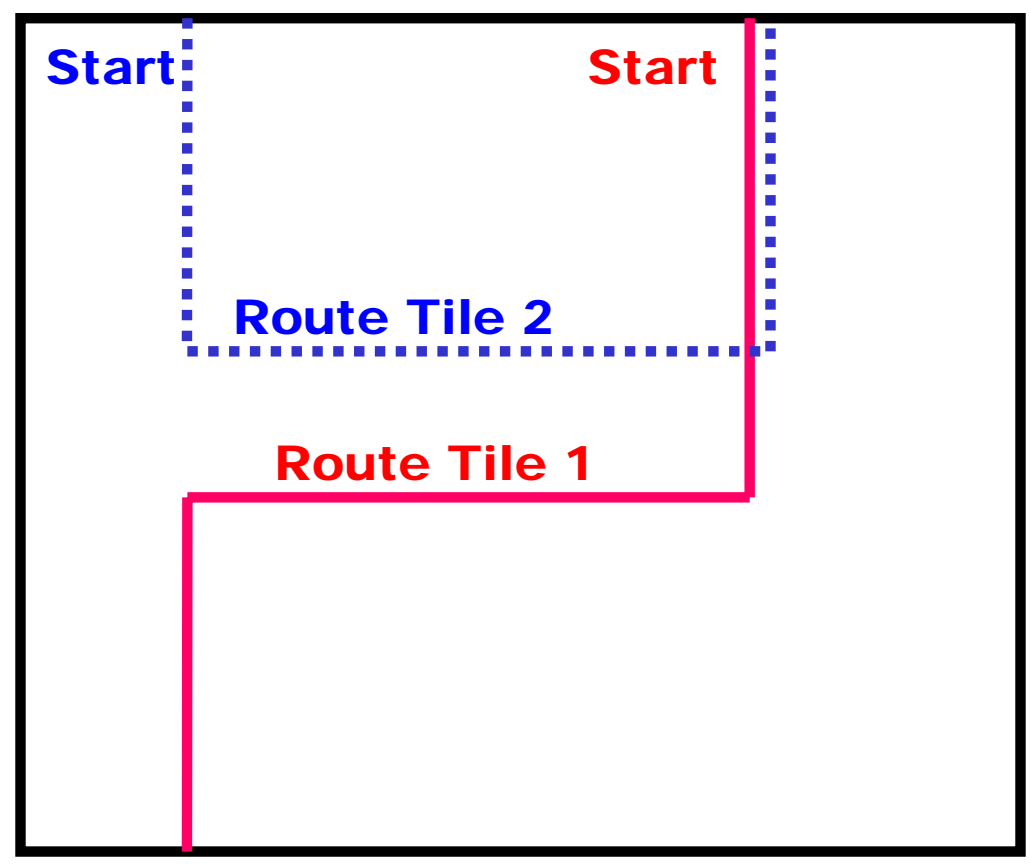

Figure 7. Moving between two sections of the route

To move to the beginning of the next portion of the route, that shown by the blue dotted line, the participant was assisted by a spotter who led them to the next starting point, which was directly opposite from where they had left the first tile, and from where they would reestablish themselves on the route. If the participant looked behind them an any point in the route, they would see their own "footprints", including at the beginning of the next tile, which assisted in orienting participants as they progressed along the route. This procedure was repeated until the participant had progressed through the six tiles that made up the entire route.

The Sony Glasstron provided the participant a three dimensional recreation of the office space showing cubicle walls, office furniture, landmarks, waypoints and virtual footprints. Virtual footprints are a "you were there” display that leaves a visible trail of 
footprints that the participant can see through the display showing their own movement to assist in orientation. (Grammenos, Filou, Papadakos, and Stephanidis, 2002)

Participants' location in the training area was tracked using IS-900 tracking system, to provide data to the Thermite computer, which presented the appropriate display to the participant while also providing data to the Dell computer which provided a display for the experimenter to monitor the participants' movement. The stealth view is the floor plan shown on a 17-inch computer monitor with the tiles indicated with black lines and the route shown with a white line. An avatar in the stealth view shows the participant's location and the virtual footprints show where they have walked.

To familiarize participants with the MR environment, a familiarization session was conducted prior to their memorization period so as to avoid any MR environment specific learning impact on participants' rehearsal time. Two tiles that had been modeled but were beyond the periphery of the tiles through which the test route passed were used in this familiarization session. Each participant donned and was fitted with the BARS ensemble, then led to a starting point in the training area that did not correspond to the starting point of the test route. While standing on the edge of the space that defined each tile, the participant was oriented to the boundaries of the tiles by identifying the 4 corners of the tile shown with blue tape on the beige colored carpet. They were instructed on the specifics of the scaling factor, that each step they took in the rehearsal space was worth 3 steps in the actual space, and that the actual space would be represented by 6 tiles that worked like pages in an atlas. It was pointed out that while it was possible to walk through walls and furniture in this environment, there was no advantage to doing so. Finally they were told that to successfully complete the route they were about to learn, 
they would have to walk outside the bounds of the tile, past the blue lines, and within 3 seconds of doing so, the Glasstron display would turn black. They were to stop moving until instructed as to where they should move to pick up the continuation of the route. For this familiarization however, they were free to roam through the space to become familiar with the look and feel of the environment. Once the participant walked outside the boundary of the tile they were re-positioned at the opposite side of the tile to show them how they would pick up where they had left the tile, which included asking the participant to look behind them to see their own footprints as an orientation aid. When they indicated that they understood the concept and felt familiar with it, a process accomplished in a span of 15 minutes on average, the MR participant was removed from the rehearsal area, completed a simulator sickness inventory, and doffed the BARS ensemble, after which they were given 15 minutes to study the route as in the other 2 conditions.

At the end of the 15 minute study period the participant donned the BARS ensemble and moved into the rehearsal space with the spotter. During this rehearsal phase, participants' errors were corrected after it was clear that they were committed to a particular movement. For example if the participant were to turn right at an intersection instead of left, the experimenter would wait until it was clear that the participant had moved in the wrong direction before the experimenter would say "Stop". The participant determined their next correct move by making as many trial moves as necessary until the experimenter no longer said, "Stop". The virtual footprints could be used by the participant to review where they had been, to assist in making their corrections. After each rehearsal trial, the participant was asked to complete a simulator sickness inventory, 
and after the third rehearsal also doffed the BARS ensemble and moved to the actual $4^{\text {th }}$ floor office space where they performed a single scored traversal of the route.

The effectiveness of the training was assessed using data gathered during the traversal of the actual route without using the paper map, correction from the experimenter or the BARS ensemble. Participants were instructed that speed and accuracy in traversal of the path were of equal importance. At two points along the route, from which participants could not see either the beginning or end of the route, the participants were stopped in front of a clipboard hanging from a cubicle wall, on which was posted an $81 / 2 \times 11$ piece of paper showing a circle with an $\mathrm{X}$ in the center, and the numbers 12, 3, 6, and 9 around the edge for orientation points (See Appendix B). They were asked to imagine themselves standing on the $\mathrm{X}$ facing the 12, and to mark where they believed the starting point of the route was in relation to where they were standing, by writing an S on the circle, and to mark where they believed the end of the route was by writing an $\mathrm{E}$ on the circle. 


\section{CHAPTER FOUR: DATA ANALYSIS}

This chapter describes the data analysis for the study. The first section outlines the experimental variables, self-report measures, and demographics collected in the study. In the second section, the preliminary data for the three experimental conditions on the performance measures are examined.

\section{$\underline{\text { Description of Variables and Measures }}$}

Each of the 60 participants was assigned a participant number for use in tracking data while maintaining participants' anonymity. Demographic information that was gathered for use in data analysis included gender, age, own belief of spatial orientation and time spent using computers and maps. A sample of this questionnaire can be found in Appendix E.

In addition to the demographic data listed above, participants’ pre-experiment scores were gathered from three spatial abilities tests: the Cube Comparison and Surface Development tests from the Manual for Kit of Factor-Referenced Cognitive Tests, 1976, and the spatial orientation subtest of the Guilford-Zimmerman Aptitude Test. Scores on these tests are positively related to spatial abilities, that is, the higher the score earned, the better the participants’ ability in the spatial skill measured by each test.

Two other pre-experiment questionnaires were used to evaluate participants’ possible susceptibility to sickness in virtual environments, as well as to monitor symptoms that might appear during MR exposure. The Motion History Questionnaire was used (Kennedy, et al., 2001), RSKA Form MHQ-1, Rev. 5/01. This questionnaire 
captured participants’ past experience with motion sickness, asked them to compare themselves to others by estimating the likelihood of becoming motion sick in a situation where various percentages of other people might get motion sick, and if they would volunteer for an experiment where various percentages of other people did get motion sick. On a separate page a matrix was presented that listed 14 situations in which one would experience motion, from aircraft through motorcycles, and asked the participants their preference for these situations (Like, Neutral or Dislike), and to mark any symptoms they had experienced in any of these situations. This questionnaire was scored as described by Kennedy, et al. (2001) with each scale that was anchored with a "never" condition scored as 0 points at the lower end and "always" or "Extremely" scored as 4 points at the higher end. Questions with “yes” or "no” answers were scored 1 or 0 respectively. The questions captured frequency of airsickness, seasickness, motion sickness under other conditions, susceptibility to motion sickness, willingness to volunteer for an experiment likely to cause motion sickness, and frequency of experiencing dizziness on an annual basis. The situations from question 15 that were used in the data analyses were scored as 1 if marked by the participants and 0 if not marked, and limited to aircraft, flight simulator, roller coaster, other carnival device, and long train or bus trip, as described by Kennedy et al. (2001) and illustrated in Table 1.

The Simulator Sickness Questionnaire (SSQ) developed by Robert S. Kennedy of RSK Assessments, Inc. was used as a screening tool to be certain that participants weren’t experiencing any symptoms of illness that might cause them to experience simulator sickness while in the MR environment, and as a monitoring tool throughout the rehearsal and transfer of training testing. The questions from the symptom checklist that 
are the basis for the four measures of simulator sickness were used as discussed in Kennedy et al. (1992), and listed in Table 2, capturing 18 items from the Pre and Post Exposure Symptom Checklist, with possible responses and corresponding scores for each item ranging from None $=0$, to Slight $=1$, Moderate $=2$, and Severe $=3$. These scores were then used to calculate the general simulator sickness factor of Total Severity of sickness, and the three symptom clusters of Nausea, Oculomotor and Disorientation. These values were calculated using both the original unit weighting procedure as described by Kennedy et al. (1992), and an un-weighted procedure as used by personnel at the Army Research Institute, Orlando, FL (Knerr, et al., 1998). While the SSQ is a valuable tool, it was based on data gathered from Navy pilots, which according to Knerr et al. caused data gathered from college students to show standard deviations of 34.4, 25.6 and 21.1 instead of the consistent standard deviation of 15 for each of the three subscales of disorientation, nausea, and Oculomotor effects found in Kennedy et al.'s data (1998). By not applying the weights Knerr et al. found that not only did their standard deviations not change the relative order of the means as the weightings had done, but it also allows for rapid interpretation where a score of 3 is one severe symptom (or 3 mild ones) and a score of 1 is one mild symptom.

Participants’ responses to the Simulator Sickness Questionnaire Exposure Checklist were captured at various times throughout the course of the experiment, dependent upon the assigned experimental condition. Those participants who drew the route on a floor plan as rehearsal, and those who walked through the actual office space, each completed the checklist at the end of their rehearsal period, before performing the transfer of training tests of route traversal and orientation localization. MR condition 
participants completed the checklist after the familiarization exposure to the MR environment, after each of the three rehearsal trials in the environment, and after performing the transfer of training tests, which was typically 10 minutes after their exposure to the MR environment.

Four performance variable data sets were gathered, with the first two variable sets used to measure route knowledge which included total time to traverse the route, and number of traversal errors (wrong turns). The second two variable sets, used to measure survey knowledge, included data from the participants' input on each of the orientation localization tasks located at two reporting stations along the route. This survey knowledge was based on the absolute error between the actual location of the start and end points of the route from each of the two reporting stations, and the participants' input as to where they believed the start and end points of the route to be located. The location of the two orientation localization stations and the start and end points of the route are illustrated in Appendix A.

Prior to analysis, descriptive statistics were examined for each experimental variable, and all variables were screened for normality, outliers and missing values, and appropriate transformations applied. Each of the performance variables, that is Number of traversal errors, Total time to complete route, and the variables that captured the delta value in degrees of error from each orientation localization station (Error to Start Station 1, Error to End Station 1, Error to Start Station 2 and Error to End Station 2) were transformed by using the mean to replace any missing data, along with the top five univariate outliers as identified by SPSS Explore. Throughout the following statistical analyses SPSS version 11.5 was used, with alpha set to .05 unless otherwise specified. 
Throughout the following statistical analyses SPSS version 11.5 was used, with alpha set to .05 unless otherwise specified.

\section{Effectiveness of MR on Performance Measures (Route and Survey Knowledge)}

Route knowledge: A between subjects analysis of variance was conducted, in which the independent variable was rehearsal condition (paper map, walker, mixed reality). All variables were screened for normality, outliers and missing values, and appropriate transformations applied as described previously to ensure the data met the analysis requirements. As can be seen in Table 3, the analysis of variance was significant for Total Number of Errors in Route Traversal, with $F(2,57)=6.24, p<.001$, with a partial $\eta^{2}$ of 0.18 . Participants in the walker condition averaged 0.85 errors, the MR participants 3.47 errors, and the paper map participants committed an average of 4.39 errors. Post hoc tests using a Scheffe adjustment for multiple comparisons, shows that participants in the walker condition, that is those that rehearsed the route in the actual office space, consistently performed better than those in either the paper or mixed reality conditions.

Table 3. Analysis of Variance for Traversal Errors

\begin{tabular}{lcccc}
\hline Source & df & $F$ & $\eta^{2}$ & $p$ \\
\hline Total Traversal Errors & 2 & $6.24^{* *}$ & .18 & .000 \\
Error & 57 & & & \\
${ }^{* *} p<.01$ & & & &
\end{tabular}

Post hoc tests using a Scheffe adjustment for multiple comparisons, shows that participants in the walker condition, that is those that rehearsed the route in the actual office space, consistently performed better than those in either the paper or mixed reality conditions. 
Table 4. Post Hoc with Scheffe adjustment for Traversal Errors

\begin{tabular}{|c|c|c|c|}
\hline Condition & Condition & Mean Difference & $p$ \\
\hline \multirow{2}{*}{ Paper Map } & Walker & $3.545^{* *}$ & .005 \\
\hline & Mixed Reality & .927 & 675 \\
\hline \multirow[t]{2}{*}{ Walker } & Paper Map & $-3.545 * *$ & .005 \\
\hline & Mixed Reality & $-2.6186 *$ & .050 \\
\hline \multirow[t]{2}{*}{ Mixed Reality } & Paper Map & -.9271 & 675 \\
\hline & Walker & $2.618^{*}$ & .05 \\
\hline
\end{tabular}

A between subjects ANOVA was conducted using the IV condition and the DV Total Time to Complete the Route. The Total Time was significant at $F(2,57)=9.42, p$ $<.000$, and a partial $\eta^{2}$ of .25. Participants in the walker condition averaged 1.99 minutes to complete the route, MR participants averaged 3.25 minutes, and paper map participants 3.77 minutes.

Table 5. Analysis of Variance for Time to Complete Route

\begin{tabular}{lcccc}
\hline Source & $\mathrm{df}$ & $F$ & $\eta^{2}$ & $p$ \\
\hline Total Time to Complete & 2 & $9.416^{* *}$ & .18 & .000 \\
Error & 57 & & & \\
${ }^{* *} p<.01$ & & & & \\
\end{tabular}

Post hoc tests using a Scheffe adjustment for multiple comparisons, shows that participants in the walker condition, that is those that rehearsed the route in the actual office space, consistently performed better than those in either the paper or mixed reality conditions.

Table 6. Post Hoc with Scheffe adjustment for Time to Complete

\begin{tabular}{llrc}
\hline \multicolumn{1}{c}{ Condition } & \multicolumn{1}{c}{ Condition } & Mean Difference & $p$ \\
\hline Paper Map & Walker & $1.786^{* *}$ & .000 \\
& Mixed Reality & .523 & .222 \\
\multirow{2}{*}{ Walker } & Paper Map & $-1.786^{* *}$ & .000 \\
\multirow{3}{*}{ Mixed Reality } & Mixed Reality & $-1.264^{* *}$ & .004 \\
& Paper Map & -.9271 & .675 \\
& Walker & $1.264^{* *}$ & .004 \\
\hline
\end{tabular}

**mean differences significant at the .01 level 
Survey knowledge: A between subjects analysis of variance was conducted using rehearsal condition as the independent variable rehearsal condition (paper map, walker, mixed reality). All variables were screened for normality, outliers and missing values, and appropriate transformations applied as described previously to ensure the data meets the analysis requirements. As can be seen in Table 7, the analysis of variance was not significant for the any of these measures.

\begin{tabular}{lccc}
\multicolumn{4}{l}{ Table 7. Analysis of Variance for Survey Knowledge } \\
\hline Source & $\mathrm{df}$ & $F$ & $p$ \\
\hline Error to Start Station 1 & 2 & 2.366 & .103 \\
Error & 57 & & \\
Error to End Station 1 & 2 & 1.390 & .257 \\
Error & 57 & & \\
Error to Start Station 2 & 2 & 1.407 & .253 \\
Error & 57 & & \\
Error to End Station 2 & 2 & .032 & .969 \\
Error & 57 & & \\
\hline
\end{tabular}

\section{Comparison of Spatial Abilities Tests to Performance Measures on Survey and Route Knowledge}

While data was gathered for each participant's performance on three tests of spatial abilities, and on both route and survey knowledge, as measured during transfer of training testing for what were considered to be spatial tasks, there was no indication that performance on one might be related to the other. To examine the relationship between tests of spatial abilities and route knowledge test performance measures, a correlation analysis was conducted using SPSS. Specifically the variables were: Cube Comparison Test, Surface Folding Test, Guilford-Zimmerman Spatial Orientation Test, Total Time to Complete Route, and the Number of Traversal Errors with adjustment for outliers as described above. Table 8 shows the descriptive statistics that describe the performance of 
participants on the spatial abilities tests, while Table 9 displays the correlations among the variables.

Table 8. Descriptive Statistics of Spatial Abilities Tests

\begin{tabular}{lrrr}
\hline & Cube Comparison & Surface Development & Guilford-Zimmerman \\
\hline Mean & 17.78 & 36.15 & 11.81 \\
Standard Error M & 1.45 & 1.89 & 1.19 \\
Median & 18.50 & 35.50 & 11.25 \\
Standard Deviation & 11.23 & 14.65 & 9.21 \\
Minimum & -1.00 & 9.00 & -5.50 \\
Maximum & 43.00 & 64.00 & 39.75 \\
\hline
\end{tabular}

The specific hypothesis that the three tests of spatial abilities would be related is only supported for the relationship between Surface Development and Cube Comparison, with a correlation of 0.381 significant at the 0.01 level, and between Surface Development and the Guilford-Zimmerman task where the correlation was 0.451, which was also significant at the 0.01 level. A relationship between the Cube Comparison and the Guilford-Zimmerman tests was not established in this study.

Route knowledge: Neither of the performance variables correlated with the tests of spatial abilities, however, the Total Number of Errors made during route traversal was positively correlated with the time to complete the route, with 0.639 , significant at the 0.01 level. Logically, this indicates that as the number of errors increased, so did the amount of time required to complete the route.

Table 9. Correlation of Spatial Abilities Tests and Route Knowledge

\begin{tabular}{llllll}
\hline Variables & Cube & Surface & G-Z & Time & Errors \\
\hline Cube Comparison & 1.00 & & & & \\
Surface Development & $0.381^{* *}$ & 1.00 & & & \\
Guilford-Zimmerman & 0.214 & $0.451^{* *}$ & 1.00 & & \\
Total Time to Complete & -0.105 & -0.031 & -0.174 & 1.00 & \\
Traversal Error & 0.044 & -0.201 & -0.146 & $0.639^{* *}$ & 1.00 \\
\hline ** Correlation is significant at the 0.01 level (2 tailed) & & &
\end{tabular}


Survey knowledge: To examine the relationship between the tests of spatial abilities and survey knowledge performance measures, a separate correlation analysis was conducted using SPSS. Specifically the variables were: Cube Comparison Test, Surface Folding Test, Guilford-Zimmerman Spatial Orientation Test, Error Start 1, Error End 1, Error Start 2 with outliers and missing data transformed as described above. Table 10 displays the correlations between the variables, where the correlations among the three spatial abilities tests are again apparent. Correlational relationships are apparent among the measures of survey knowledge and the three spatial abilities tests. The Cube Comparison test is negatively correlated with the Error to End from Station 2, with a correlation of -.259 , while the Guilford-Zimmerman Test is negatively correlated with the Error to Start from Station 2, with a correlation of -.260, both significant at the 0.05 level. The Surface Development Test is negatively correlated with Error to Start from Station 1, at -.275, and Error to End from Station 1, with -.294 at the 0.05 level, and Error to Start from Station 2, with -.364 at the 0.01 level. The Error to the End of the Route from Station 1 is positively related to the Error value for identifying the location of the End of the Route from Station 2, with a correlation of .255, which is significant at the 0.05 level.

It would appear that as scores on the Surface Development test increase, so do the scores on the Cube Comparison, and Guilford-Zimmerman tests, so that higher scores on Surface Development, which indicates greater ability in this type of spatial task is related to greater ability in comparison of cubes and in spatial orientation as measured by the Guilford-Zimmerman test. As these scores on standardized tests of Spatial Abilities increase, however, participants' localization scores decrease significantly. This would be 
interpreted as the ability in spatial tasks improves, so does the ability to localize the beginning and end of the route, since these values are difference error values, between the actual location of the point of interest and the location the participant expected the point to be, thus the lower score is more desirable. As the amount of Error to the End of the Route from Station 1 increases, so does the amount of Error to the End of the Route from station 2 increase, showing some consistency in the participants' perceptions of the route and the layout of the environment through which it passed.

An additional analysis of the relationship between the three tests of spatial abilities and the performance scores for this experiment was conducted. This analysis was suggested by the work of Diaz and Sims (2003), in which participant's scores on the Guilford Zimmerman were used to split the group in two: high spatial ability and low spatial ability based on the median value obtained from their sample. Analysis of variance was conducted for each of the performance scores using the dichotomized spatial abilities technique for all three tests; however, none of the results were significant or assisted in further explanation of the relationship between performance on standardized tests, and performance on experimental task.

Table 10. Correlation between Spatial Abilities and Survey Knowledge Performance

\begin{tabular}{llllllll}
\hline Variables & Cube & Surface & G-Z & Start 1 & End 1 & Start 2 & End 2 \\
\hline Cube Comparison & 1.00 & & & & & & \\
Surface Development & $.381^{* *}$ & 1.00 & & & & & \\
Guilford-Zimmerman & .214 & $.451^{* *}$ & 1.00 & & & & \\
Error Start Station 1 & -.054 & $-.275^{*}$ & -.208 & 1.00 & & & \\
Error End Station 1 & -.194 & $-.294^{*}$ & -.181 & $.437^{* *}$ & 1.00 & & \\
Error Start Station 2 & -.248 & $-.364^{* *}$ & $-.260^{*}$ & .077 & .195 & 1.00 & \\
Error End Station 2 & $-.259^{*}$ & -.165 & -.081 & -.061 & $.255^{*}$ & .122 & 1.00 \\
\hline
\end{tabular}

* correlation is significant at the 0.05 level (2 tailed)

**correlation is significant at the 0.01 level (2 tailed) 


\section{Learning in Mixed Reality}

As has been described previously, the model of the office space was broken into tiles, and the tiles were explained to participants as being similar to the pages of an atlas, so that when they ended a route segment at the edge of one tile they would start the route again from that same point at the edge of the next tile. While the participants were never shown a drawing of the environment or the tiles, the experimenter, to monitor the participants' current position and progress through the environment, used the diagram of the environment presented on the second computer. With a sampling rate of approximately once per each second, data was captured that was saved to a file with a time stamp, an X coordinate, which was the participant's head pitch, a Y coordinate, which was the head roll, and a $\mathrm{Z}$ coordinate, that was the head yaw, and the tile coordinate number. That position data was also used to generate an avatar, which showed the experimenter where the participant was in the environment. The graphic below shows the environment with black lines that indicate the boundaries of the tiles, a white line that describes the route, and the coordinate names for each of the tiles. 


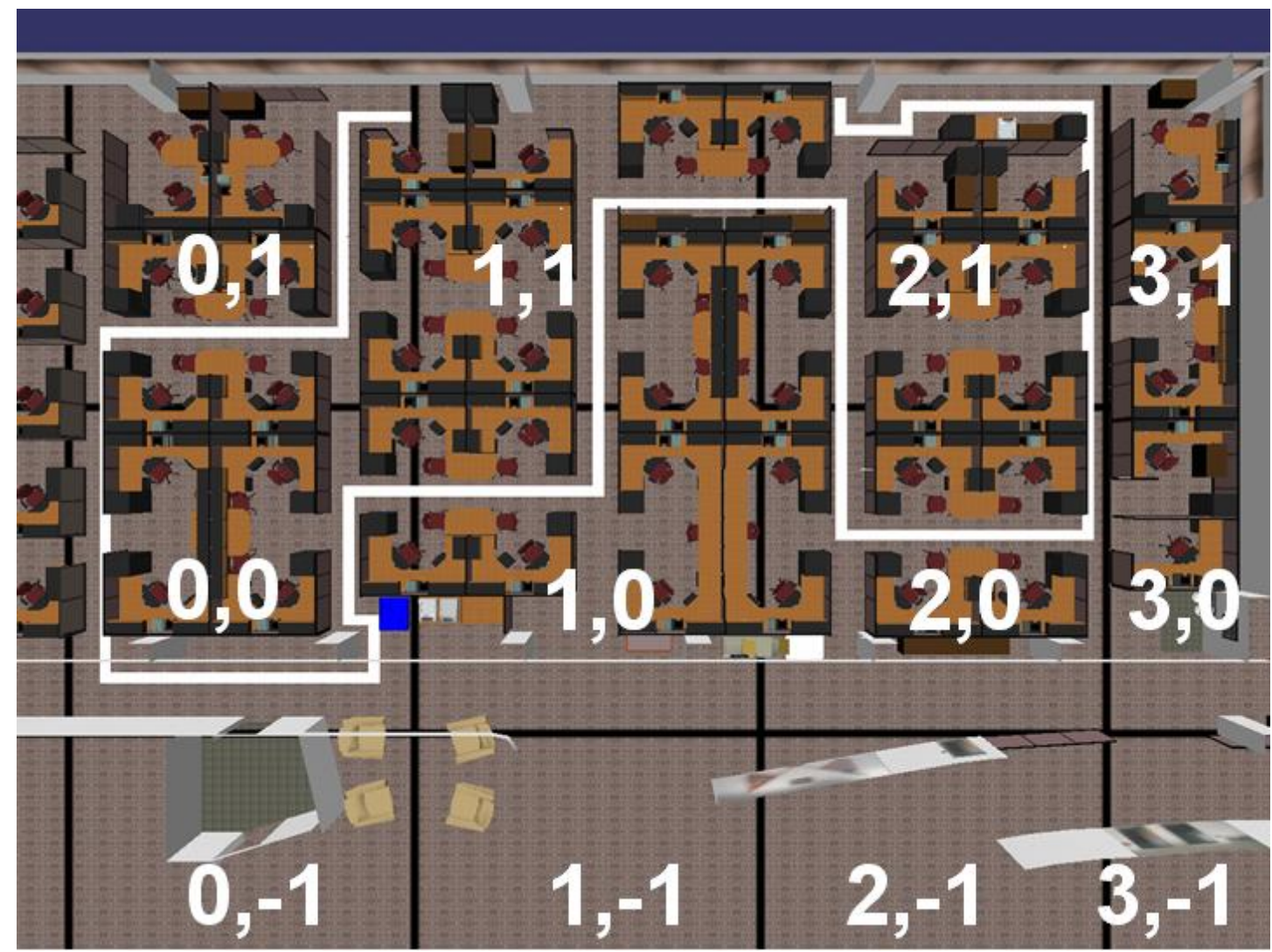

Figure 8. Model Diagram Showing Tiles, Tile Coordinates and Route

To show that learning occurred over the three rehearsal trials, an analysis of variance was performed using SPSS, with an alpha level of .05, unless otherwise stated. Because of an unequal number of participants in gender, which occurred when the data for the first male subject was inadvertently over-written on the Thermite computer, the data for the first female participant was removed from further analysis, chosen on the basis of matching the first male participant. The grouping variable was rehearsal trial (1, 2 and 3) and all variables were screened for normality, outliers and missing values. There were 18 subjects 50\% of which were female, each of which performed three rehearsal trials. As can be seen in Table11 the analysis of variance was significant for rehearsal trial number and the total time spent on each trial for each tile, except Tile 1,1: 
Tile 0,1 with an overall mean of 65.29 is significant at $F(2,51)=9.161, p<.01$. Tile 0,0 with an overall mean of 94.18 is significant at $F(2,51)=23.64, p<.01$, while Tile 1,0 , with an overall mean of 30.90 is significant at $F(2,51)=3.58, p<.05$. Tile 1,1 does not show significance over the three rehearsal trials, however, that may be because the traversal requirement for that tile included continuing on the straight path the participant had been following and making a single right turn, as can be seen in Figure 10. Tile 2,1 with an overall mean of 106.76 is significant at $F(2,51)=5.97, p<.01$, and Tile 2,0 shows an overall mean of 47.11 , with significance at $F(2,51)=7.19, p<.01$.

Table 11. ANOVA for Time spent in each Tile over 3 Trials

\begin{tabular}{|c|c|c|c|}
\hline Source & df & $F$ & $p$ \\
\hline Tile 0,1 & 2 & $9.161 * *$ & .000 \\
\hline Error & 51 & & \\
\hline Tile 0,0 & 2 & $23.64 * *$ & .000 \\
\hline Error & 51 & & \\
\hline Tile 1,0 & 2 & $3.58 *$ & .035 \\
\hline Error & 51 & & \\
\hline Tile 1,1 & 2 & .893 & .416 \\
\hline Error & 51 & & \\
\hline Tile 2,1 & 2 & $5.970 * *$ & .005 \\
\hline Error & 51 & & \\
\hline Tile 2,0 & 2 & $7.187 * *$ & .000 \\
\hline Error & 51 & & \\
\hline
\end{tabular}

Post hoc comparisons, with a Scheffe adjustment compared the three trials to find if there was a significant difference between the first, second and third trials in each tile. In tile 0,1 there was a significant decrease in the time required to traverse the tile, with Trial 1 showing a mean of 101.14 seconds, Trial 2 a mean of 58.03 seconds and Trial 3 36.71 seconds on average. Tile 0,0 also showed a significant decrease over all three trials with Trial 1 showing a mean of 170.37 seconds, Trial 265.34 seconds, and Trial 3 at 46.84 seconds. In Tile 1,0 there was a significant decrease between Trial 1 with a mean 
of 37.00 seconds and Trial 3 with a mean of 26.57 seconds, but there was no significant difference between either Trial 1 or Trial 3 with Trial 2 showing an average of 29.12 seconds to traverse the tile. There were no significant differences among the three trials in Tile 1,1. In both Tile 2,1 and 2,0, there was a significant difference between the first and third trials but not the first and second or second and third. Tile 2,1 has a mean traversal time for Trial 1 of 158.44 seconds and for Trial 3 of 66.91 seconds. Tile 2,0 has a mean time of 61,19 for Trail 1 and 34.43 for Trial 3.

Table 12. Means of Three Rehearsal Trial Times by Tile

\begin{tabular}{|c|c|c|c|c|c|c|c|}
\hline $\begin{array}{l}\text { Trial } \\
\#\end{array}$ & & Tile 0,1 & Tile 0,0 & Tile 1,0 & Tile 1,1 & Tile 2, 1 & Tile 2, 0 \\
\hline \multirow[t]{2}{*}{1.00} & Mean & 101.1367 & 170.3706 & 37.0022 & 39.9667 & 158.4422 & 61.1922 \\
\hline & Std. Deviation & 68.48461 & 94.09564 & 17.39638 & 20.19743 & 117.05832 & 32.08240 \\
\hline \multirow[t]{2}{*}{2.00} & Mean & 58.0300 & 65.3400 & 29.1222 & 36.8728 & 94.9239 & 45.7161 \\
\hline & Std. Deviation & 37.96886 & 32.19971 & 10.81415 & 22.37378 & 66.01114 & 13.80851 \\
\hline \multirow[t]{2}{*}{3.00} & Mean & 36.7111 & 46.8439 & 26.5756 & 31.3233 & 66.9100 & 34.4339 \\
\hline & Std. Deviation & 14.75236 & 15.77776 & 5.10074 & 15.85823 & 42.84484 & 11.66436 \\
\hline \multirow[t]{2}{*}{ Total } & Mean & 65.2926 & 94.1848 & 30.9000 & 36.0543 & 106.7587 & 47.1141 \\
\hline & Std. Deviation & 52.61464 & 79.16664 & 12.76709 & 19.62408 & 88.74530 & 23.61206 \\
\hline
\end{tabular}

\section{MR and Simulator Sickness}

To assess the possibilities of simulator sickness occurring in this MR environment an analysis was conducted of participants' past experience with motion and motion sickness, as well as their perception of the likelihood of experiencing motion sickness, and the occurrence of simulator sickness symptoms during or after exposure to the MR.

A multivariate analysis of variance was conducted using SPSS and there were no multivariate or univariate within cell outliers at $p<.01$. Results of evaluation of assumptions of normality, homogeneity of variance-covariance matrices, linearity, and multicollinearity were satisfactory, with rehearsal condition, (paper map, walker, MR) as 
the independent variable, and the questions of interest from the Motion History Questionnaire as the dependent variables. Specifically, questions examined included frequency of airsickness, seasickness, experience of motion sickness under any other conditions, susceptibility to motion sickness (self rating), willingness to volunteer for a study in which $85 \%$ of participants became motion sick, comparison of self to stated frequency of dizziness in the general population, the total number of motion situations the participant liked, felt neutral toward, and disliked, along with the total number of situations in which participants vomited, experienced nausea, or experienced no symptoms of motion sickness.

With the use of Wilks' criterion, the combined DVs were not significantly effected by membership in rehearsal condition, with $F(20,86)=.641, p>.05$, and a partial $\eta^{2}$ of .13. This lack of significance was taken as an indication that there was no difference among the participants of the three rehearsal conditions with respect to the prediction or expectation of motion sickness, and therefore simulator sickness while in the MR rehearsal condition.

Participants' perceptions of their own susceptibility to motion sickness was then compared to weighted and un-weighted simulator sickness scores calculated from participants' responses to the simulator sickness inventories completed throughout their experimental trial. A multivariate analysis of variance was conducted using SPSS version 11.5, with an alpha level of .05 unless otherwise stated. There were no multivariate or univariate within cell outliers at $p<.01$. Results of evaluation of assumptions of normality, homogeneity of variance-covariance matrices, linearity, and multicollinearity were satisfactory. 
With the use of Wilks' criterion, the combined DVs were not significantly effected by participants' beliefs concerning their susceptibility of motion sickness, with $F$ $(16,100)=.559, p>.05$, and a partial $\eta^{2}$ of .08. This lack of significance was taken as an indication that there was no connection between participants' expectations about motion sickness and actual ratings of simulator sickness throughout the three conditions of the experiment.

The tendency for participants to experience symptoms of simulator sickness with exposure to the MR was examined through analysis of variance using SPSS version 11.5, and an alpha level of .05. All participants had completed pre and post test SSQ inventories, however, this procedure resulted in a maximum of two reports from the walkers and the paper map rehearsal participants, and a maximum of six from the MR participants. Therefore, for this analysis to examine simulator sickness while comparing MR to the non-MR conditions, only the single post test inventory from the walkers and paper map participants were used, while the post third rehearsal inventories from the MR participants were used. Given the cumulative properties of simulator sickness, this was considered to be the worse case for the MR participants. There were no outliers, and the results of the evaluation of assumptions of normality were satisfactory.

Table 13. ANOVA Post Test SSQ (W) Inventory

\begin{tabular}{lccc}
\hline Source & df & $F$ & $p$ \\
\hline SSQ TS W & 2 & .136 & .873 \\
Error & 57 & & \\
SSQ N W & 2 & .019 & .982 \\
Error & 57 & & \\
SSQ O W & 2 & .626 & .538 \\
Error & 57 & & \\
SSQ D W & 2 & 1.702 & .191 \\
Error & 57 & &
\end{tabular}




\begin{tabular}{lccc}
\multicolumn{4}{l}{ Table 14. ANOVA Post Test SSQ (R) Inv } \\
\cline { 2 - 4 } Source & $\mathrm{df}$ & $F$ & $p$ \\
\hline SSQ TS R & 2 & .128 & .880 \\
Error & 57 & & \\
SSQ N R & 2 & .019 & .982 \\
Error & 57 & & \\
SSQ O R & 2 & .626 & .538 \\
Error & 57 & & \\
SSQ D R & 2 & 1.702 & .191 \\
Error & 57 & & \\
\hline
\end{tabular}

With the use of weighted Simulator Sickness Questionnaire values, there was no difference among the three rehearsal conditions. Total Severity of sickness was not significant with $\mathrm{F}(2,57)=.136, p>.05$, nor was Nausea with $F(2,57)=.019, p>.05$, or Oculomotor with $F(2,57)=.626, p>.05$, or Disorientation with $F(2,57)=1.702, \mathrm{p}>$ .05 .

A separate analysis was conducted using the un-weighted SSQ values, and there were no differences among the three rehearsal conditions in symptomology. Total Severity of sickness was not significant with $F(2,57)=.128, p>.05$, nor was Nausea with $F(2,57)=.019, p>.05$, or Oculomotor with $F(2,57)=.626, p>.05$, or Disorientation with $F(2,57)=.191, \mathrm{p}>.05$. The results of these analyses would indicate that rehearsal conducted in this type of MR does not produce significant symptoms of simulator sickness. 


\section{CHAPTER FIVE: CONCLUSION}

From inception, the basis for this research was exploratory in nature, to determine if training in a mixed environment, as provided by the Battlefield Augmented Reality System (BARS), was effective. If it is effective, there are multiple training situations with needs that are either partially, or not at all, met by current technologies, for which BARS may be an answer. An effective mission rehearsal tool for dismounted infantry to use as they learn their way through an unknown environment has the potential to enhance Soldiers' capabilities and improve survivability rates. Given current technology in information acquisition in the form of cartography, and imagery from multiple sources, there are multiple methods for gathering the data to input to this potential mission rehearsal tool, as well as the software and hardware to construct it. This experiment has addressed the following hypotheses:

1. Rehearsing a wayfinding task using MR will result in effective route and or survey knowledge, based on performance scores that are comparable to those achieved through rehearsal that is based on drawing a route on a floor plan (a paper map), or rehearsal in the actual test environment.

Rehearsal of the wayfinding task in this experiment was most effective in decreasing the time and errors of the participants who walked through the actual office space. This result should not be surprising, but should also be observed to not be an acceptable form of mission rehearsal, given a remote and or hostile environment, where the area may be under threat. Participants who rehearsed the route by drawing it on a floor plan performed at a level that was indistinguishable from those who rehearsed in the mixed reality environment. While it was expected that the kinematic learning inherent to 
walking through the route, whether it was in the actual space or the MR, this experiment was not designed to determine if maps could be done away with, only to see if another type of rehearsal might be as good as or better than drawing on maps. The experimental conditions that were not addressed include map study, and the combined effect of paper map rehearsal, and or map study, with mixed reality, is likely to be the more realistic case for mission rehearsal. Soldiers will likely have maps available, but to have walked through the environment beforehand can only enhance the Soldiers' understanding of their surroundings. The repeated comments gathered from participants in the mixed reality condition such as “This looks like I was just here” and “There’s that pole I kept having trouble with”, lead one to believe that this is a tool to continue to explore and apply.

The minimal difference among the survey knowledge measurements shows that mixed reality was as good as walking through the actual facility or drawing the route on a map. The mean difference between mixed reality and walking in locating the end of the route from the orientation localization station number one was about 29 degrees. This type of knowledge might have been enhanced in either of these conditions if participants had been given the opportunity to divert from the learned route to develop a better cognitive map of their surroundings, creating short cuts that might later turn to escape routes. With the addition of a map of the environment Soldiers would likely learn the ins and outs of an environment thoroughly before arriving at the actual location.

A point to keep in mind in this discussion of performance based on rehearsal in the mixed reality environment, is that this environment was not only a virtual environment, it was one that scaled down the size of the environment such that each step 
a participant took in the MR was equal to 3 steps in the real space, and the MR condition required participants to learn the route in chunks as they moved through the 6 tiles, with a minimum of 7 tile changes ( 2 tiles were used twice). During the design stages of this project, there were two concerns that prompted the use of the spotter within the MR space. One was the chance that a participant might become disoriented, and or have difficulty with balance, as they walked through the MR environment. The other concern was that participants would have difficulty with the tiling concept, and need active assistance in moving from one tile to the next. In both cases, however, the concern was not supported by these participants. After having experienced the familiarization trail, participants appeared quite comfortable in the environment, walking through the space without self-protective actions, such as searching the area with their hands as they walked. In addition, participants overall were quick to pick up on the tiling procedure, automatically moving to the start of the next tile without specific instruction within the first two to three tile changes.

While additional research on the scaling and tiling factors is likely warranted, to determine that the effect may be carried over to other environments or tasks, it may also be related to how people interact with maps, where a scaling factor of 1 to 15,000 is common in orienteering maps, and 1 to 25,000 in military maps.

2. The spatial abilities tests Cube Comparison, and Surface Development from the Manual for Kit of Factor-Referenced Cognitive Tests, (Ekstrom, et al., 1976), and the Guilford-Zimmerman Aptitude Survey test of spatial orientation (Guilford, 1948) will correlate with participants' performance on the three performance measurement tasks of time to traverse the learned route, number of errors committed in the timed trial of route 
traversal, and the ability to be oriented enough to locate the position of the beginning and ending of the route from two separate locations..

This hypothesis was partially supported by the data. In correlation analyses the Surface Development test was found to correlate with the Cube Comparisons test and the Guilford-Zimmerman spatial orientation test, but there was no relationship between the Guilford-Zimmerman and the Cube Comparison test, or between any of these three tests of spatial abilities, and the participants’ performance on total time to complete the route, or the number of errors made while traversing the route. There was a positive relationship between the time required to complete the route and the number of errors made. The correlation of localization performance scores with the spatial abilities tests were negative, showing that the higher one scored on the standardized tests, the lower their error scores, that is the better they were at locating the beginning and end of the route at locations from which they could not see either the beginning or the end. There was a positive correlation between the ability to locate the end of the route at the first station from the second station, showing consistency in performance.

3. Rehearsal of route traversal in the mixed reality environment will be successful as a training tool as evidenced by improved performance, measured by decreased total time for each successive trial in the mixed reality environment.

This hypothesis was generally supported by the data, with the time to complete each MR rehearsal decreasing significantly over time. In addition 5 of 6 tiles showed a significant decrease in the amount of time required to traverse that tile between the first and third trials. Time spent in learning the route in this condition varied widely from a maximum first trail of 25 minutes to a minimum first trial of 3.2 minutes, and a 
maximum third trial of 8.5 minutes to 2.2 minutes. Some of this variability might be explained by the improvement in efficiency on the part of the experimenter and the spotter in moving participants through the condition, while some of it could be blamed on an issue referred to as "avatar excursions".

There were two sets of SoniStrips installed end to end above the MR environment, and passing through the locations directly below the gap between the two sets often caused an anomaly in the environment such that the participant was suddenly faced with a tumbling effect in the visual display of the MR, while on the base computer the experimenter could watch the avatar that was supposed to be indicating the location of the participant in the MR environment, instead fly rapidly away from that location in any possible direction. These events occurred without warning or identifiable pattern. By the end of the program, however, the experimenter became adept at "catching” the avatar as it started to "fly" by clicking on it using the mouse, which would stop both the avatar's flight, and the tumbling of the environment in the participants' display. Evidence for this possibility is that early participants in the program show longer rehearsal times and increased numbers of avatar excursions, than those who were involved later in the program.

One recommendation for future research would be to attempt to utilize a different tracking system. One of the goals of the BARS program is that it be a wireless system, whether it receives input from GPS when outdoors or from a tracking system indoors, which in this case was the InterSense IS-900. Another indoor system that might be more stable with regard to avatar excursions might be a wireless Flock of Birds System. 
4. Participation in route rehearsal in the MR environment will not cause greater symptomology of simulator sickness than in the non-MR environments, based on the proprioceptive feedback provided by physically walking through the virtual environment, reducing the vestibular conflict brought on by sensing motion visually, while remaining physically stationary.

This hypothesis was supported by the data gathered using the Simulator Sickness Questionnaire and processed by using both the weighted values developed by Kennedy et al. (1993), and the non-weighted values as per Knerr et al. (1998).

The presence of proprioceptive feedback in the mixed reality condition was expected to produce performance scores that were better than paper map rehearsal, and the same as walking through the actual facility. And although that hypothesis wasn't supported completely, it is very likely that proprioceptive feedback is what led to the lack of simulator sickness among the mixed reality participants. Future research might include a direct comparison of learning route and survey knowledge through this type of mixed reality and through a virtual environment system through which users move by manipulating an input device such as a mouse or joystick, while physically remaining stationary.

The exploration and confirmation of the training capabilities of MR as implemented using BARS is an important step in the development and application of the system to the U.S. Army training mission. This experiment was designed to examine one potential training area in a small controlled environment, which can be used as the foundation for experimentation with more complex tasks such as wayfinding through an urban environment, and or in direct comparison to more established virtual environments 
to determine strengths and areas for improvement as BARS is considered as an addition to the training mission.

As the power of electronics increases with reductions in cost over time, the utility and affordability of augmented, virtual and mixed reality environments will also increase. The possibility of having small, easy-to-configure mobile units would expand the ability of the Army to enhance its training efforts in the future. To continue this line of research has the potential to expand training opportunities into scenarios not previously thought possible, improve Soldier performance and ultimately their safety and survivability. 


\section{APPENDIX A}

FLOOR PLAN: ROUTE, LANDMARKS AND LOCALIZATION 


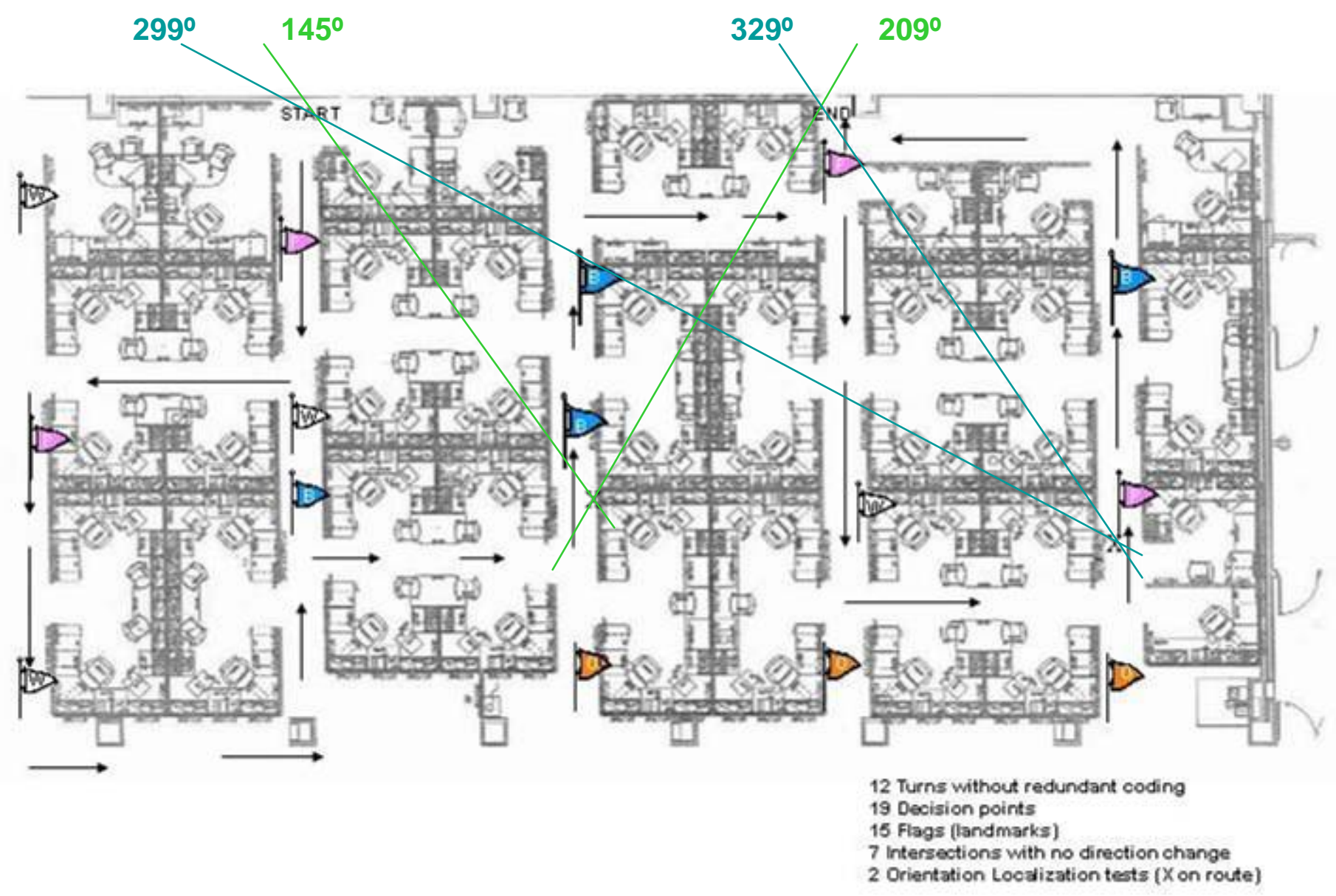

Figure 9. Diagram of environment showing all information. 
APPENDIX B

ORIENTATION LOCALIZATION 


\section{Orientation Localization}

1. Stand facing the wall where the clipboard is hanging.

2. Imagine yourself standing at the $X$ facing the $\mathbf{1 2}$.

3. Use the pen to place an $S$ on the circle where the start of the route is located in reference to the $X$.

4. Use the pen to place an $E$ on the circle where the end of the route is located in reference to the $X$.

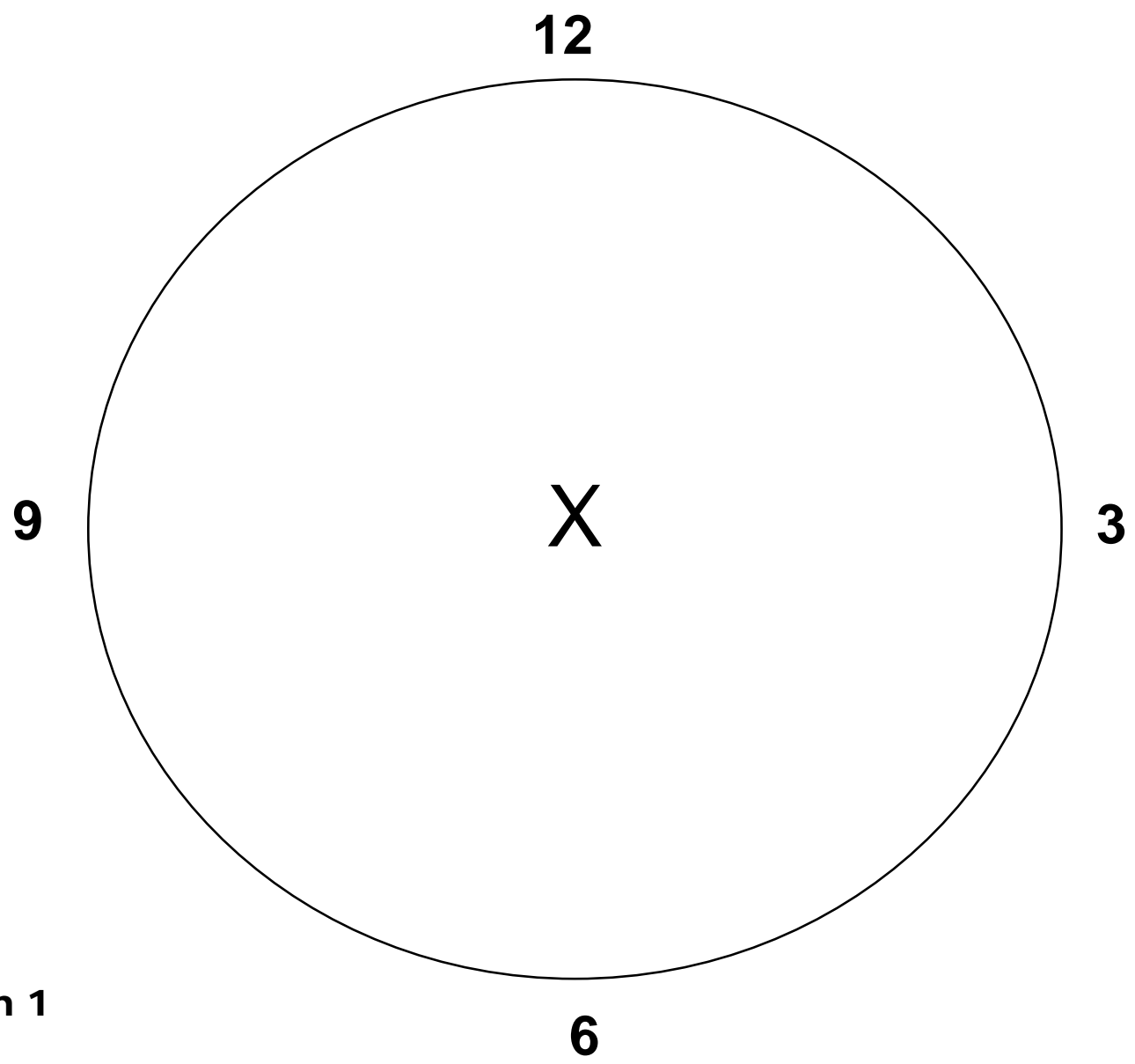

Figure 10. Orientation Localization Page 
APPENDIX C

FLOOR PLAN USED FOR PAPER MAP REHEARSAL 


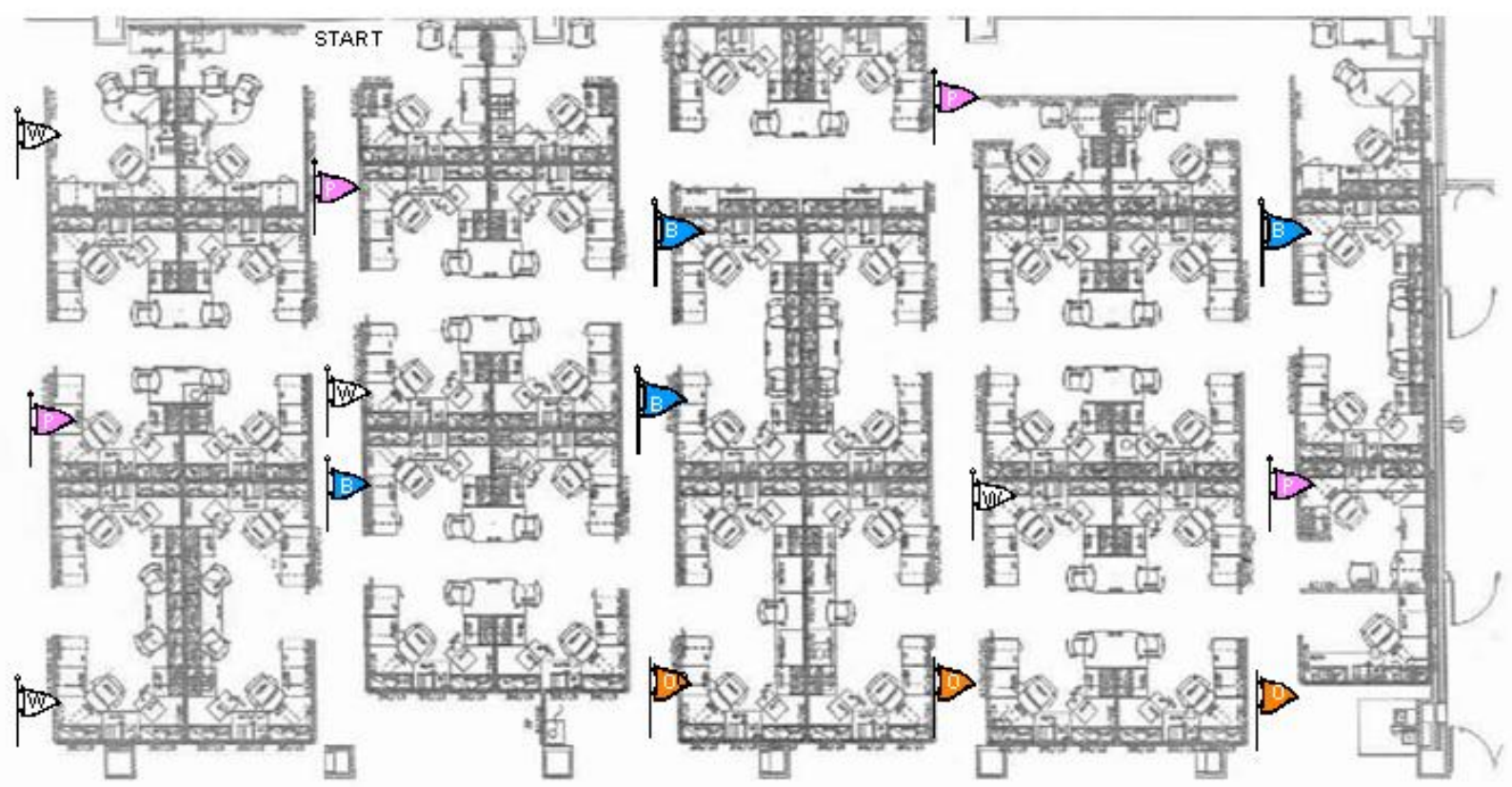

Figure 11. Floor Plan Used for Paper Map Rehearsal 
APPENDIX D

EXPERIMETER SCRIPTS AND PROCEDURES 


\section{Experimental Procedures}

(Read this to each MR condition participant)

The Experimenter: "Thank you for participating in this experiment. This experiment is part of an Augmented Reality research project sponsored by the Army Research Institute. In general, augmented reality systems add information to the real world using a computer. You will be wearing a vest with a mobile augmented reality system that weighs about 5 pounds. There is a display that is attached to an adjustable headband. The display is designed to adjust to fit over most eyeglasses. The display's position is adjustable and we will help you in adjusting it to a comfortable position. The entire test should take less than three hours.

Your task involves learning to navigate a specific route through an office area. Before putting on the equipment, learning the route and performing the task, you will be asked to fill out an informed consent form, a demographics sheet and take two surveys concerning the way you experience motion. You will then be asked to complete three tests that are used to evaluate your spatial abilities. Do your best on the tests, go in sequence through the questions, and do not go back and redo questions unless you have finished before time is called.

Throughout the training portion of the experiment using the augmented reality equipment, you will be asked to fill out one page surveys concerning your experience in using the system.

If at any time you feel uncomfortable with the situation and want to stop the experiment, please verbalize your intent and we will stop the experiment. Otherwise, we will not respond to questions or comments during your completion of surveys, training in the MR environment, testing the actual office space, or any other tasks.

Do you have any questions so far?”

ACTION: Give the participant the Informed Consent Form and the demographics sheet. Experimenter: "Please fill out the Informed Consent Form and the demographics sheet”. 
ACTION: After the participant is done with filling out the consent form and the demographics sheet, administer Motion History Questionnaire.

Experimenter: "Please complete the Motion History Questionnaire."

ACTION: After the participant is done with the motion history questionnaire, administer the Simulator Sickness Questionnaire.

Experimenter: "Please complete the Simulator Sickness Questionnaire."

ACTION: After the participant is done with the Simulator Sickness Questionnaire, administer the Spatial Orientation Test.

Experimenter: "Please complete the following Cube Comparison Test. Read over the instructions on the first page carefully and complete the practice session. You should mark your answers on the test page. Do not turn the page until you are told to do so. Please indicate when you have finished with the first page." ACTION: When participant has indicated they are prepared to continue...

Experimenter: "You will have 3 minutes to complete one page of cube comparisons. Work as quickly and accurately as possible. Are you ready?”

ACTION: When the participant indicates they're ready, start the stopwatch as you say: Experimenter: "Go"

ACTION: When 3 minutes have passed say:

Experimenter: "Stop" "You will have 3 minutes to complete one more page of cube comparisons. Work as quickly and accurately as possible. Are you ready?”

ACTION: When the participant indicates they're ready, start the stopwatch as you say:

Experimenter: "Go"

ACTION: When 3 minutes have passed say:

Experimenter: "Stop" 
ACTION: After the participant is done with the Cube Comparison test, administer the Visualization test.

Experimenter: "Please complete the following Visualization Test. Read over the instructions on the first page carefully and complete the practice session. You should mark your answers on the test page. Do not turn the page until you are told to do so. Please indicate when you have finished with the first page."

ACTION: When participant has indicated they are prepared to continue...

Experimenter: "You will have 6 minutes to complete 2 pages of the visualization test. Work as quickly and accurately as possible. Are you ready?”

ACTION: When the participant indicates they're ready, start the stopwatch as you say: Experimenter: "Go"

ACTION: When 6 minutes have passed say:

Experimenter: "Stop. You will have 6 minutes to complete 2 more pages of the visualization test. Work as quickly and accurately as possible. Are you ready?” ACTION: When the participant indicates they're ready, start the stopwatch as you say:

Experimenter: "Go"

ACTION: When 6 minutes have passed say:

Experimenter: "Stop

ACTION: Remove the visualization test, and present the participant the Spatial Orientation test book. BE SURE TO GIVE THEM A SCANTRON

Experimenter: "Please complete the following exercise. Read over the instruction page carefully and complete the practice session on pages 1, 2, and 3. Please do NOT record your responses to the practice items. When you have finished the practice session and are ready to begin, please let me know. Please do NOT begin working on the remainder of the exercise until instructed to do so".

ACTION: Make sure that you tell them NOT TO WRITE IN THE BOOKLET and record their answers ONLY on the scantron provided! After they let you know that they 
are done going over the sample items give them a scantron and ask them again to record their answers on the scantron ONLY! Hand them the scantron.

Experimenter: "Please record your answers on the scantron only. Be sure to mark your answer to Test question \#8 on the scantron as \#1 and continue from there. You have 10 minutes to work on the test. Do not spend too much on one item. If you are finished before the time is called, you may go back and check your work. If you are not sure about the answer to any item, you may guess, but avoid wild guessing. Your score will be the number of correct answers minus a fraction of the number wrong. Are you ready? ACTION: When the participant indicates they're ready, start the stopwatch as you say:

\section{Experimenter: "Go"}

ACTION: At the end of 10 minutes:

\section{Experimenter: “Stop.”}

ACTION: Collect the scantron and test booklet.

Experimenter: "Please listen carefully to the following instructions. Your task is to study a set of directions, then practice traversing the route that those directions describe. You will have 15 minutes to study those directions. Do you have any questions?” ACTION: If the participant has no questions, hand them their booklet with the proper Pre-brief statement and directions.

Experimenter: "Please read the Pre-brief statement. When you are finished please let me know.”

ACTION: When the participant has read the pre-brief statement, have them don the BARS system and conduct the familiarization task. (See separate instruction.) When the familiarization is complete have the participant return to the testing area, and when they are ready, start the stopwatch as you say:

Experimenter: "You have 15 minutes to study these directions, starting now."

ACTION: When 15 minutes are up, stop the watch, and retrieve the notebook. 
Experimenter: "Your practice session will be conducted using an augmented reality system to project a virtual model of the office space through which you will walk using the directions you've studied. Remember each step you take in the model is equal to 3 steps in the real office space. You will have 3 opportunities to walk through the entire route. Remember that when you get to the edge of an area the screen will turn gray or black. When that happens please let us know so we can move you to the next proper position. In addition to the intersections and aisles of office space, you will see the survey flags to use as cues and you will be able to monitor your own movement through the model by the footprints you leave behind you.

If you make a mistake you will be asked to stop, and will have to discover the correct move without instruction and try again. This will be repeated until you make the proper move and have progressed completely through the model.

Please put on the augmented reality system and get comfortable with it”. ACTION: Assist the participant to put on the equipment and adjust the display. When comfortable, move them to the starting point of the first chunk of the route.

Experimenter: "You are about to begin. Do you have any questions?”

ACTION: Perform 3 practice runs through the model. At the end of each practice trial present the POST TEST Symptom Checklist. When finished -

Experimenter: "This completes the practice portion of the experiment. Please remove the augmented reality system.”

ACTION: When the equipment has all been removed and stowed give an additional POST TEST Symptom Checklist to complete. Retrieve the form when finished then Experimenter: "We will now move to the test environment on the $4^{\text {th }}$ floor of this building."

ACTION: Move to the $4^{\text {th }}$ floor and to the starting point. Be sure the survey flags and clipboards are in place prior to the participant's arrival to the area. Lead the participant to the starting point by the most direct route. 
Experimenter: "You will now perform 1 timed trial of the route you practiced previously. At 2 points along the route you will find a clipboard hanging from the wall. You must stop at each, and without removing the clipboard from the wall; imagine yourself standing at the center of the circle on the $\mathrm{X}$, with your nose pointed toward the 12. Without looking around the room, write an $S$ on the circle where you think the start of the route is in relation to your current position, and an E on the circle where you think the end of the route is in relation to your current position. Do you have any questions?” ACTION: When there are no further questions

Experimenter: "You may begin." START THE STOP WATCH

ACTION: Follow the participant and count the number of errors the make. Be sure they stop and perform the localization task properly. When they reach the end STOP THE STOP WATCH

Experimenter: "This completes the test portion of the experiment. We will now return to the practice area."

ACTION: When you have returned to the training area, be sure to pay them if they are participating for cash payment, then give them a copy of the Debrief Statement along with the Psychology Research Experience Evaluation Form for Participants, and thank them for their participation. 


\section{Instructions for Experimenter to Read for BARS Familiarization}

First we will help you don the BARS system. Please let the technicians assist you in donning the vest, and the head mounted display. The vest is adjustable using the three straps across the front. Please feel free to request help in adjusting the straps. The head mounted display is also adjustable, but the band must be snug around your head to keep the display from moving while in use.

Please be careful not to catch any of the cables with your hands or pull on them. Anytime the display presents an empty gray field please tell the technicians.

You will be able to see the floor by looking under the bottom edge of the display.

The image you will see is a model of an office environment made up of cubicles. You should be able to see walls, ceiling, floor, and office furniture along with survey flags, small colored squares hanging from thin sticks that protrude from the walls of the cubicle aisles. If you want to see where you've been, look at the floor through the display directly behind you and you will see your own footprints.

Your movement through this environment will be 3 times faster than in the real world. Each step you take in the model is worth 3 steps in the real world.

The model is broken into sections. When you reach the end of a section the display will turn a solid gray and you should stop walking. You will then be directed to move to one of the yellow spots on the floor identified with a black letter.

When the display appears and you can see it clearly, look straight ahead, take 2 steps straight forward and stop. Turn your head slowly to the left. (Pause) Now turn slowly to the right. (Pause). Return slowly to looking forward. 
Now, turn your head quickly to the left, quickly to the right, and return quickly to center. Note the difference in the appearance of the model depending on the speed with which you move your head. Look at the floor through the display and turn around to see your own footprints directly behind you.

Please take a few minutes to walk through this space. Be careful to stay in the aisles because there is nothing to stop you from walking through a wall, which is likely to be disorienting. Be sure to turn left and right to walk into cubicles and see the furniture in them. Note the presence of survey flags.

When you have reached the edge of the section the display will look gray. Please let the technician know when that happens so you can be directed to your next starting point.

When you have been repositioned and the office model appears in the display you will be in the same position as you were before the display turned gray. Please use this section to explore the area, as you like. When you feel familiar with moving through the model please let us know so we may continue with the next part of the experiment.

Do you have any questions? 


\section{MR Rehearsal Instructions}

You will be positioned at the starting point of the route, with your back to the windows. Please walk the route that you have learned.

If you make an error, you will be told to stop, and must determine how to correct your movement without input from the technician.

When the display shows a solid gray please stop and allow the technician to re-position you at the starting point of the next tile.

You will perform 3 practice trials of the entire route through the model.

Do you have any questions? 
(Read this to each WALKING condition participant)

The Experimenter: "Thank you for participating in this experiment. This experiment is part of an Augmented Reality research project sponsored by the Army Research Institute. In general, augmented reality systems add information to the real world using a computer. The entire test should take less than two hours.

Your task involves learning to navigate a specific route through an office area. Before learning the route and performing the task, you will be asked to fill out an informed consent form, a demographics sheet and take two surveys concerning the way you experience motion. You will then be asked to complete three tests that are used to evaluate your spatial abilities. Do your best on the tests, go in sequence through the questions, and do not go back and redo questions unless you have finished before time is called.

If at any time you feel uncomfortable with the situation and want to stop the experiment, please verbalize your intent and we will stop the experiment. Otherwise, we will not respond to questions or comments during your completion of surveys, training, or testing.

Do you have any questions so far?”

ACTION: Give the participant the Informed Consent Form and the demographics sheet. Experimenter: "Please fill out the Informed Consent Form and the demographics sheet”.

ACTION: After the participant is done with filling out the consent form and the demographics sheet, administer Motion History Questionnaire.

Experimenter: "Please complete the Motion History Questionnaire.”

ACTION: After the participant is done with the motion history questionnaire, administer the Simulator Sickness Questionnaire.

Experimenter: “Please complete the Simulator Sickness Questionnaire.” 
ACTION: After the participant is done with the Simulator Sickness Questionnaire, administer the Spatial Orientation Test.

Experimenter: "Please complete the following Cube Comparison Test. Read over the instructions on the first page carefully and complete the practice session. You should mark your answers on the test page. Do not turn the page until you are told to do so. Please indicate when you have finished with the first page.”

ACTION: When participant has indicated they are prepared to continue...

Experimenter: "You will have 3 minutes to complete one page of cube comparisons. Work as quickly and accurately as possible. Are you ready?”

ACTION: When the participant indicates they're ready, start the stopwatch as you say: Experimenter: “Go"

ACTION: When 3 minutes have passed say:

Experimenter: “Stop” "You will have 3 minutes to complete one more page of cube comparisons. Work as quickly and accurately as possible. Are you ready?”

ACTION: When the participant indicates they're ready, start the stopwatch as you say:

Experimenter: "Go"

ACTION: When 3 minutes have passed say:

Experimenter: "Stop”

ACTION: After the participant is done with the Cube Comparison test, administer the Visualization test.

Experimenter: "Please complete the following Visualization Test. Read over the instructions on the first page carefully and complete the practice session. You should mark your answers on the test page. Do not turn the page until you are told to do so. Please indicate when you have finished with the first page.”

ACTION: When participant has indicated they are prepared to continue...

Experimenter: "You will have 6 minutes to complete 2 pages of the visualization test. Work as quickly and accurately as possible. Are you ready?” 
ACTION: When the participant indicates they're ready, start the stopwatch as you say:

\section{Experimenter: "Go"}

ACTION: When 6 minutes have passed say:

Experimenter: "Stop. You will have 6 minutes to complete 2 more pages of the visualization test. Work as quickly and accurately as possible. Are you ready?”

ACTION: When the participant indicates they're ready, start the stopwatch as you say:

\section{Experimenter: "Go"}

ACTION: When 6 minutes have passed say:

Experimenter: "Stop

ACTION: Remove the visualization test, and present the participant the Spatial

Orientation test book. BE SURE TO GIVE THEM A SCANTRON

Experimenter: "Please complete the following exercise. Read over the instruction page carefully and complete the practice session on pages 1,2 , and 3. Please do NOT record your responses to the practice items. When you have finished the practice session and are ready to begin, please let me know. Please do NOT begin working on the remainder of the exercise until instructed to do so".

ACTION: Make sure that you tell them NOT TO WRITE IN THE BOOKLET and record their answers ONLY on the scantron provided! After they let you know that they are done going over the sample items give them a scantron and ask them again to record their answers on the scantron ONLY! Hand them the scantron.

Experimenter: "Please record your answers on the scantron only. Be sure to mark your answer to Test question \#8 on the scantron as \#1 and continue from there. You have 10 minutes to work on the test. Do not spend too much on one item. If you are finished before the time is called, you may go back and check your work. If you are not sure about the answer to any item, you may guess, but avoid wild guessing. Your score will be the number of correct answers minus a fraction of the number wrong. Are you ready? ACTION: When the participant indicates they're ready, start the stopwatch as you say: 


\section{Experimenter: "Go"}

ACTION: At the end of 10 minutes:

Experimenter: "Stop.”

ACTION: Collect the scantron and test booklet.

Experimenter: "Please listen carefully to the following instructions. Your task is to study a set of directions, then practice traversing the route that those directions describe. You will have 15 minutes to study those directions. Do you have any questions?” ACTION: If the participant has no questions, hand them their booklet with the proper Pre-brief statement and directions.

Experimenter: "Please read the Pre-brief statement. When you are finished please let me know."

ACTION: When the participant has read the pre-brief statement, and when they are ready, start the stopwatch as you say:

Experimenter: "You have 15 minutes to study these directions, starting now."

ACTION: When 15 minutes are up, stop the watch, and retrieve the notebook.

Experimenter: "Your practice session will be conducted by walking through the actual office space. You will have 3 opportunities to walk through the entire route. In addition to the intersections and aisles of office space, you will see the survey flags to use as cues.

If you make a mistake you will be asked to stop, and will have to discover the correct move without instruction and try again. This will be repeated until you make the proper move and progressed completely through the route. We will now move to the test environment on the $4^{\text {th }}$ floor of this building."

ACTION: Move to the $4^{\text {th }}$ floor and to the starting point. Be sure the survey flags and clipboards are in place prior to the participant's arrival to the area. Lead the participant to the starting point by the most direct route.

Experimenter: "You will now perform 3 practice trials of the route you have studied as previously described.” 
ACTION: Perform 3 practice runs through the space. At the end of the practice session present the POST TEST Symptom Checklist. When finished Experimenter: "This completes the practice portion of the experiment.

You will now perform 1 timed trial of the route you practiced previously. At 2 points along the route you will find a clipboard hanging from the wall. You must stop at each, and without removing the clipboard from the wall; imagine yourself standing at the center of the circle on the $\mathrm{X}$, with your nose pointed toward the 12 . Without looking around the room, write an $S$ on the circle where you think the start of the route is in relation to your current position, and an $\mathrm{E}$ on the circle where you think the end of the route is in relation to your current position. Do you have any questions?”

ACTION: When there are no further questions

Experimenter: "You may begin.” START THE STOP WATCH

ACTION: Follow the participant and count the number of errors the make. Be sure they stop and perform the localization task properly. When they reach the end STOP THE STOP WATCH

Experimenter: "This completes the test portion of the experiment. We will now return to the practice area."

ACTION: When you have returned to the training area, be sure to pay them if they are participating for cash payment, then give them a copy of the Debrief Statement along with the Psychology Research Experience Evaluation Form for Participants, and thank them for their participation.

(Read this to each MAP condition participant)

The Experimenter: "Thank you for participating in this experiment. This experiment is part of an Augmented Reality research project sponsored by the Army Research Institute. In general, augmented reality systems add information to the real world using a computer. The entire test should take less than two hours. 
Your task involves learning to navigate a specific route through an office area. Before learning the route and performing the task, you will be asked to fill out an informed consent form, a demographics sheet and take two surveys concerning the way you experience motion. You will then be asked to complete three tests that are used to evaluate your spatial abilities. Do your best on the tests, go in sequence through the questions, and do not go back and redo questions unless you have finished before time is called.

If at any time you feel uncomfortable with the situation and want to stop the experiment, please verbalize your intent and we will stop the experiment. Otherwise, we will not respond to questions or comments during your completion of surveys, training, or testing.

Do you have any questions so far?”

ACTION: Give the participant the Informed Consent Form and the demographics sheet.

Experimenter: "Please fill out the Informed Consent Form and the demographics sheet”.

ACTION: After the participant is done with filling out the consent form and the demographics sheet, administer Motion History Questionnaire.

Experimenter: "Please complete the Motion History Questionnaire.”

ACTION: After the participant is done with the motion history questionnaire, administer the Simulator Sickness Questionnaire.

Experimenter: “Please complete the Simulator Sickness Questionnaire.”

ACTION: After the participant is done with the Simulator Sickness Questionnaire, administer the Spatial Orientation Test.

Experimenter: "Please complete the following Cube Comparison Test. Read over the instructions on the first page carefully and complete the practice session. You should mark your answers on the test page. Do not turn the page until you are told to do so. Please indicate when you have finished with the first page.” 
ACTION: When participant has indicated they are prepared to continue...

Experimenter: "You will have 3 minutes to complete one page of cube comparisons. Work as quickly and accurately as possible. Are you ready?”

ACTION: When the participant indicates they're ready, start the stopwatch as you say:

Experimenter: "Go"

ACTION: When 3 minutes have passed say:

Experimenter: "Stop" "You will have 3 minutes to complete one more page of cube comparisons. Work as quickly and accurately as possible. Are you ready?”

ACTION: When the participant indicates they're ready, start the stopwatch as you say:

Experimenter: "Go"

ACTION: When 3 minutes have passed say:

Experimenter: "Stop”

ACTION: After the participant is done with the Cube Comparison test, administer the Visualization test.

Experimenter: "Please complete the following Visualization Test. Read over the instructions on the first page carefully and complete the practice session. You should mark your answers on the test page. Do not turn the page until you are told to do so. Please indicate when you have finished with the first page." ACTION: When participant has indicated they are prepared to continue...

Experimenter: "You will have 6 minutes to complete 2 pages of the visualization test. Work as quickly and accurately as possible. Are you ready?”

ACTION: When the participant indicates they're ready, start the stopwatch as you say:

Experimenter: "Go"

ACTION: When 6 minutes have passed say:

Experimenter: "Stop. You will have 6 minutes to complete 2 more pages of the visualization test. Work as quickly and accurately as possible. Are you ready?” 
ACTION: When the participant indicates they're ready, start the stopwatch as you say:

\section{Experimenter: "Go"}

ACTION: When 6 minutes have passed say:

Experimenter: "Stop

ACTION: Remove the visualization test, and present the participant the Spatial Orientation test book. BE SURE TO GIVE THEM A SCANTRON

Experimenter: "Please complete the following exercise. Read over the instruction page carefully and complete the practice session on pages 1, 2, and 3. Please do NOT record your responses to the practice items. When you have finished the practice session and are ready to begin, please let me know. Please do NOT begin working on the remainder of the exercise until instructed to do so".

ACTION: Make sure that you tell them NOT TO WRITE IN THE BOOKLET and record their answers ONLY on the scantron provided! After they let you know that they are done going over the sample items give them a scantron and ask them again to record their answers on the scantron ONLY! Hand them the scantron.

Experimenter: "Please record your answers on the scantron only. Be sure to mark your answer to Test question \#8 on the scantron as \#1 and continue from there. You have 10 minutes to work on the test. Do not spend too much on one item. If you are finished before the time is called, you may go back and check your work. If you are not sure about the answer to any item, you may guess, but avoid wild guessing. Your score will be the number of correct answers minus a fraction of the number wrong. Are you ready? ACTION: When the participant indicates they're ready, start the stopwatch as you say:

Experimenter: "Go"

ACTION: At the end of 10 minutes:

Experimenter: "Stop."

ACTION: Collect the scantron and test booklet. 
Experimenter: "Please listen carefully to the following instructions. Your task is to study a set of directions, then practice the route that those directions describe. You will have 15 minutes to study those directions. Do you have any questions?”

ACTION: If the participant has no questions, hand them their booklet with the proper Pre-brief statement and directions.

Experimenter: "Please read the Pre-brief statement. When you are finished please let me know."

ACTION: When the participant has read the pre-brief statement, and when they are ready, start the stopwatch as you say:

Experimenter: "You have 15 minutes to study these directions, starting now." ACTION: When 15 minutes are up, stop the watch, and retrieve the notebook. Experimenter: "Your practice session will be conducted by drawing the route on a floor plan of the actual office space. You will have 3 opportunities to draw the entire route. In addition to the intersections and aisles of office space, you will see the survey flags to use as cues.

If you make a mistake you will be asked to stop, and will have to discover the correct move without instruction and try again. This will be repeated until you make the proper move and have progressed completely through the route."

ACTION: Perform 3 practice drawings through the space. At the end of the practice session present the POST TEST Symptom Checklist. When finished -

Experimenter: "This completes the practice portion of the experiment. We will now move to the test area on the $4^{\text {th }}$ floor of this building.

ACTION: Move to the $4^{\text {th }}$ floor and to the starting point. Be sure the survey flags and clipboards are in place prior to the participant's arrival to the area. Lead the participant to the starting point by the most direct route.

Experimenter: "You will now perform 1 timed trial of the route you practiced previously. At 2 points along the route you will find a clipboard hanging from the wall. 
You must stop at each, and without removing the clipboard from the wall; imagine yourself standing at the center of the circle on the $\mathrm{X}$, with your nose pointed toward the 12. Without looking around the room, write an $\mathrm{S}$ on the circle where you think the start of the route is in relation to your current position, and an $E$ on the circle where you think the end of the route is in relation to your current position. Do you have any questions?” ACTION: When there are no further questions

\section{Experimenter: “You may begin.” START THE STOP WATCH}

ACTION: Follow the participant and count the number of errors the make. Be sure they stop and perform the localization task properly. When they reach the end STOP THE STOP WATCH

Experimenter: "This completes the test portion of the experiment. We will now return to the practice area."

ACTION: When you have returned to the training area, be sure to pay them if they are participating for cash payment, then give them a copy of the Debrief Statement along with the Psychology Research Experience Evaluation Form for Participants, and thank them for their participation. 
APPENDIX E DEMOGRAPHICS QUESTIONNAIRE 
Participant number:

Male

Female

Year in School:

YES NO

Is your vision corrected to 20/20?

Do you have any color vision deficiency? YES NO

If yes, please describe:
Date:

Age:

Major:

How many hours a week do you spend using a computer?

How many hours a week do you spend playing video games?

On a scale of 1 to 10, with one meaning you are never misoriented and 10 meaning you always have trouble finding your way around, how would you rate your sense of direction?

How often do you use a map?

Never Once a week Once a month Once a year

When you use a map do you always orient the map with north up, or do you rotate the map based on your direction of travel?
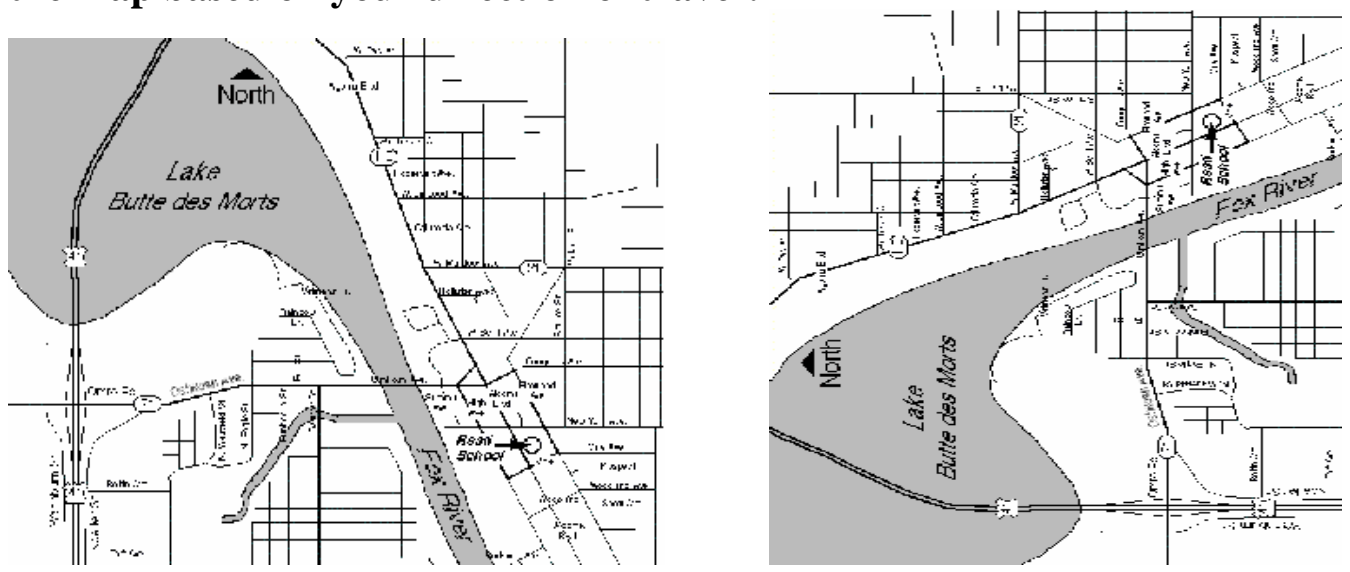
APPENDIX F

ROUTE DIRECTIONS FOR MEMORIZATION 


\section{Route Directions}

Please study the following directions to walk from one point to another along this specific route.

Stand with your back to the windows

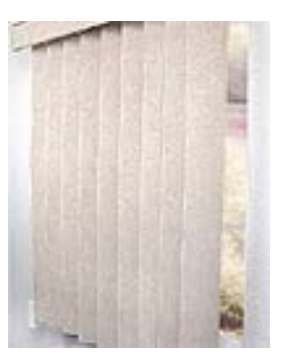

Walk forward past the pink flag

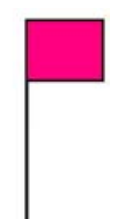

Turn right and walk to the next intersection

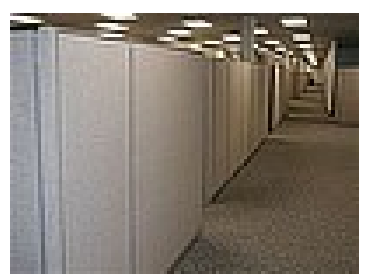

Turn left and walk past the white flag 
Turn left and walk to the intersection

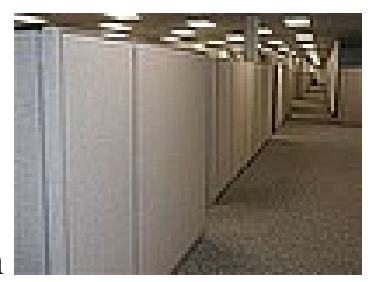

Turn left and walk toward the blue flag

Turn right and walk to the next intersection

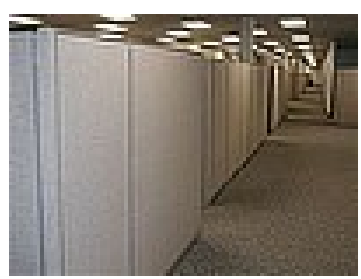

Turn left and walk past 2 blue flags

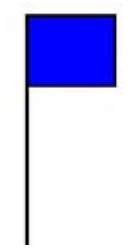

Turn right and walk to the next intersection

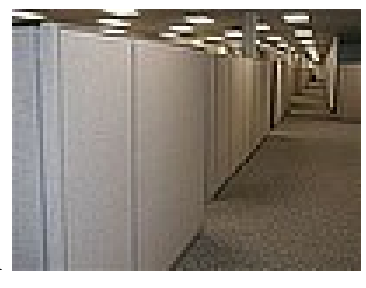

Turn right and walk past the white flag 
Turn left and walk to the next intersection

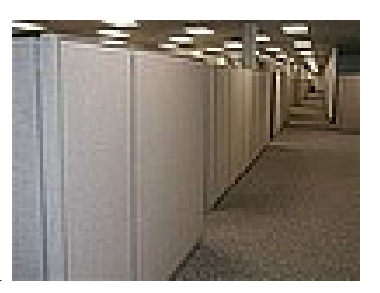

Turn left and walk past the blue flag to the next intersection

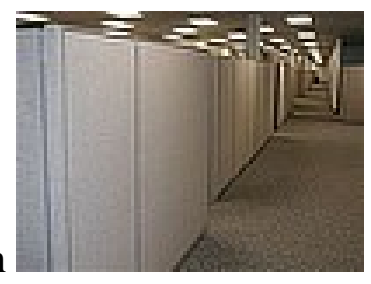

Turn left and walk to the next intersection

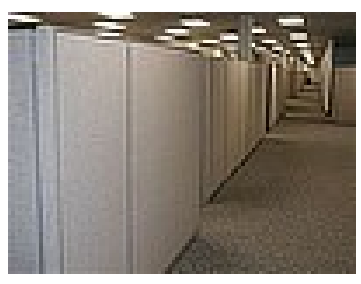

Turn right and end facing the window

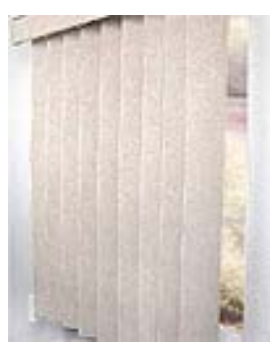


APPENDIX G

IRB APPROVAL LETTER 


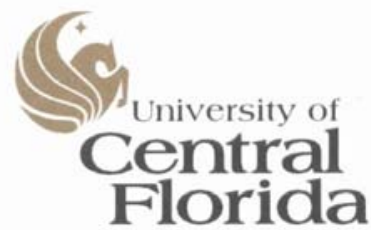

Office of Research \& Commercialization

July 11,2005

Ruthann Savage

U.S. Army Research Institute

12350 Research Parkway

Orlando, FL 32826-3276

Dear Ms. Savage:

With reference to your protocol \#05-2699 entitled, "Training Wayfaring Using the Battlefield Augmented Reality System" I am enclosing for your records the approved, expedited document of the UCFIRB Form you had submitted to our office. This study was approved on $7 / 10 / 05$ and the expiration date will be $7 / 9 / 06$. Should there be a need to extend this study, a Continuing Review form must be submitted to the IRB Office for review by the Chairman or full IRB at least one month prior to the expiration date. This is the responsibility of the investigator. Please notify the IRB office when you have completed this research study.

Please be advised that this approval is given for one year. Should there be any addendums or administrative changes to the already approved protocol, they must also be submitted to the Board through use of the Addendum/Modification Request form.

Changes should not be initiated until written IRB approval is received. Adverse events should be reported to the IRB as they occur.

Should you have any questions, please do not hesitate to call me at 407-823-2901.

Please accept our best wishes for the success of your endeavors.

Cordially,

Parbara ward

Barbara Ward, CIM

IRB Coordinator

Copies: IRB File

Richard Gilson, Ph.D.

12443 Research Parkway • Suite 302 • Orlando, FL 32826-3252 • 407-823-3778 • Fax 407-823-3299

An Equal Opportunity and Affirmative Action Institution 


\section{REFERENCES}

Allen, G.L., \& Kirasic, K.C. (1985). Effects of the Cognitive Organization of Route Knowledge on Judgments of Macrospatial Distances. Memory \& Cognition, (3) 218227

Arthur, E.J., \& Hancock, P.A., (2001). Navigation training in virtual environments, International Journal of Cognitive Ergonomics, Lawrence Erlbaum, 5(4), 387-400.

Bailey, J.H. (1994). Spatial Knowledge Acquisition in a Virtual Environment. Unpublished doctoral dissertation, University of Central Florida, Orlando.

Banker, W.P., (1997). Virtual Environments and Wayfinding in the Natural Environment, Naval Postgraduate School, Monterey, CA.

Bernatovich, D., (1999). The Effect of Presence on the Ability to Acquire Spatial Knowledge in Virtual Environments, Naval Postgraduate School, Monterey, CA.

Cevik, H., (1998). Map Usage in Virtual Environments. Naval Postgraduate School, Monterey, CA.

Columbia University, (2004) http://www1.cs.columbia.edu/graphics/ New York, NY. Retrieved from the Internet, July 21, 2004.

Conroy, R., (2001). Spatial Navigation in Immersive Virtual Environments. Doctoral Dissertation, University College London, London, England.

Darken, R.P., \& Sibert, J.L., (1993). A toolset for navigation in virtual environments. Proceedings of the $6^{\text {th }}$ Annual ACM symposium on User interface software and technology, Atlanta, GA., 157-165.

Diaz, D.D., \& Sims, V.K., (2003). Augmenting virtual environments: the influence of spatial ability on learning from integrated displays. High Ability Studies, 14 (2), 191212

Ekstrom, R.B., French, J.W., Harman, H.H., \& Dermen, D. (1976). Manual for Kit of Factor-Referenced Cognitive Tests 1976. Education Testing Service, Princeton, NJ.

Guilford, J.P., (1948). The Guilford-Zimmerman aptitude survey. Journal of Applied Psychology, 32(1) 24-34.

Goldin, S.E., \& Thorndyke, P.W. (1982). Simulating Navigation for Spatial Knowledge Acquisition. Human Factors, 24(4), 457-471. 
Grammenos, D. Filou, M., Papadakos, P., \& Stephanidis, C., (2002). Virtual Prints: Leaving trails in virtual environments. Eighth Eurographics Workshop on Virtual Environments, the Eurographics Association, Aire-la-Ville, Switzerland. 131-138.

InterSense IS-900 VET, VWT \& SimTracker Manual Doc. No. 072-00060-0F00 Revision 2.1, InterSense, Inc., Burlington, MA.

Kennedy, R.S., Lane, N.E., Berbaum, K.S., \& Lilienthal, M.G. (1993). Simulator sickness questionnaire: An enhanced method for quantifying simulator sickness. The International Journal of Aviation Psychology, 3(3), 203-220.

Kennedy, R.S., Stanney, K.M., Lane, N.E., Lanham, S., \& Kingdon, K. (2001). Use of a motion experience questionnaire to predict simulator sickness. Proceedings of HCI International 2001, New Orleans, LA.

Knerr, B.W., Lampton, D.R., Singer, M.J., Witmer, B.G., Goldberg, S.L., Parson, K.A. \& Parsons, J. (1998). Virtual environments for dismounted soldier training and performance: Results, recommendations and issues (ARI Technical Report 1089). Alexandria, VA: Army Research Institute.

Livingston, M.A., Brown, D., Gabbard, J.L., Rosenblum, L.J., Yohan, B., Julier, S.J., Swan II, J.E., \& Hix, D., (2002). An Augmented Reality System for Military Operations in Urban Terrain. Proceedings of the I/ITSEC Conference, 2002, Orlando, FL.

Milgram, P., Takemura, H., Utsumi, A., \& Kishino, F., (1994). Augmented reality: a class of displays on the reality-virtuality continuum. SPIE Vol. 2352, Telemanipulator and Telepresence Technologies, 1994.

Moeser, S.D., (1988). Cognitive Mapping in a Complex Building. Environment and Behavior, 20, 21-49.

Nemire, K., (1998). Immersive virtual environment for dismounted infantry tactics training and mission rehearsal. Proceedings of the I/ITSEC Conference, 1998, Orlando, FL.

Presson, C.C., \& Hazelrigg, M.D., (1984). Building Spatial Representations through Primary and Secondary Learning. Journal of Experimental Psychology: Learning, Memory and Cognition, 10, 716-222.

Schlender, D., Peters, O.H., \& Wienhofer, M., (2002). The effects of maps and textual information on navigation in a desktop virtual environment. Spatial Cognition and Computation 2: 421-433.

Scholl, M.J., (1993). Cognitive Maps as Orienting Schemata. Cognition, 4, 615-628. 
Stanney, K., \& Salvendy, G., (1997). Aftereffects and Sense of Presence in Virtual Environments: Formulation of a Research and Development Agenda. HCI International '97, Seventh International Conference on Human Computer Interaction, San Francisco, CA.

Swan II, J.E., Gabbard, J.L., Hix, D., Schulman, R.S., \& Kim, K., (2003). A comparative study of user performance in a map-based virtual environment. Proceedings of IEEE Virtual Reality 2003, IEEE Computer Society. 259-266.

Thorndyke, P.W., \& Hayes-Roth, B., (1982). Differences in Spatial Knowledge from Maps and Navigation. Cognitive Psychology, 14, 560-589.

Unguder, E., (2001). The Effects of Natural Locomotion on Maneuvering Task Performance in Virtual and Real Environments, Naval Postgraduate School, Monterey, CA.

Vinson, N.G., (1999). Design Guidelines for Landmarks to Support Navigation in Virtual Environments, National Research Council Canada, Institute for Information Technology, Proceedings of CHI '99, Pittsburgh, PA.

Witmer, B.G., Bailey, J.H. \& Knerr, B.W., (1996). Virtual spaces and real world places: transfer of route knowledge, International Journal of Human-Computer Studies

Wothke, W., Bock, R.D., Curran, L.T., Fairbank, B.A., Augustin, J.W., Gillet, A.H., \& Guerrero, C. (1991). Factor Analytic Examination of the Armed Services Vocational Aptitude Battery (ASVAB) and the Kit of Factor-Referenced Tests. Air Force Human Resources Laboratory Technical Report 90-67, Brooks Air Force Base, Texas. 